This peer-reviewed published paper appears as: Akcelyan, S., Lignos, D. G. and Hikino, T. (2018). "Adaptive Numerical Method Algorithms for Nonlinear Viscous and Bilinear Oil Damper Models Subjected to Dynamic Loading". Soil Dynamics and Earthquake Engineering, Vol. 113, pp. 488-502. DOI: 10.1016/j.soildyn.2018.06.021

\title{
Adaptive Numerical Method Algorithms for Nonlinear Viscous and Bilinear Oil Damper Models
}

\section{Subjected to Dynamic Loading}

Sarven Akcelyan ${ }^{\mathrm{a}}$, Dimitrios G. Lignos ${ }^{\mathrm{b}}$, Tsuyoshi Hikino ${ }^{\mathrm{c}}$

\section{ABSTRACT}

Adaptive numerical method algorithms are presented for the numerical simulation of the hysteretic behavior of nonlinear viscous and bilinear oil dampers within a finite element program for nonlinear dynamic analysis of frame structures under earthquake excitations. The adaptive algorithms are applicable for computing high-precision solutions for nonlinear viscous and bilinear oil dampers with valve relief that are typically represented mathematically with a nonlinear Maxwell model. The algorithms presented possess excellent convergence characteristics for viscous dampers with a wide range of velocity exponents and axial stiffness properties. The algorithms are implemented in an open source finite element software, and their applicability and computational efficiency is demonstrated through a number of validation examples with data that involve component experimentation as well as the utilization of fullscale shake table tests of a 5-story steel building equipped with nonlinear viscous and bilinear oil dampers.

Keywords: nonlinear viscous damper; bilinear oil damper; fluid viscous damper; supplemental damping; passive control; response modification; numerical simulation; full-scale shake table test.

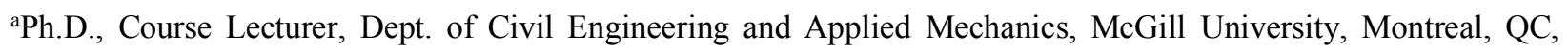
H3A $2 \mathrm{~K} 6$

${ }^{\mathrm{b}}$ Associate Professor, Dept. of Architecture, Civil and Environmental Engineering, Ecole Polytechnique Fédérale de Lausanne (EPFL), EPFL ENAC IIC RESSLab, GC B3 485, Station 18, CH-1015 Lausanne, Switzerland

${ }^{\mathrm{c}} \mathrm{Ph} . \mathrm{D}$., Section Manager, Building Construction \& Steel Structures Division, Nippon Steel and Sumikin Engineering Co., Ltd, Tokyo, Japan, Former Researcher, E-Defense, National Research Institute for Earth Science and Disaster Prevention (NIED)

\section{Introduction}

28 In the past three decades various types of supplemental damping devices have been developed and 
This peer-reviewed published paper appears as: Akcelyan, S., Lignos, D. G. and Hikino, T. (2018). "Adaptive Numerical Method Algorithms for Nonlinear Viscous and Bilinear Oil Damper Models Subjected to Dynamic Loading". Soil Dynamics and Earthquake Engineering, Vol. 113, pp. 488-502. DOI: 10.1016/j.soildyn.2018.06.021

1993; Soong and Dargush 1997; Christopoulos and Filiatrault 2006; Black and Makris 2007; Symans et al. 2008; Dong et al. 2015). To this end, viscous dampers are advantageous as the forces they develop are typically out-of-phase with displacement-induced forces within a frame building under earthquake loading (Constantinou et al. 1998). Recent earthquakes demonstrated the effectiveness of viscous dampers in response modification of conventional buildings to control structural and non-structural damage (Buchanan et al. 2011; Miranda et al. 2012; Kasai et al. 2013).

For the successful implementation of viscous dampers into the earthquake engineering design practice the availability of mathematical models that represent accurately the hysteretic response of such devices is necessary. Rigorous integration methods are essential for the numerical solution of these models when nonlinear response history analysis (NRHA) is conducted. Unlike in solid viscoelastic dampers (Chang et al. 1995) the temperature dependency of fluid viscous dampers is relatively low (Kasai et al. 2004b;

41 Symans et al. 2008). In contrast with the idealized assumption of purely viscous dashpot models, viscous dampers show stiffness dependency characteristics that generally undermine the effectiveness of a viscous damper (Makris and Constantinou 1991). Although a number of researchers, have studied the effect of axial stiffness of viscous dampers on the seismic performance of frame buildings (Constantinou et al. focused on linear viscous dampers. In the case of nonlinear viscous dampers, a common practice has been to neglect the damper axial stiffness (Pekcan et al. 1999; Ramirez et al. 2001; Lin and Chopra 2002; Hwang et al. 2008; Diotallevi et al. 2012). This is a convenient assumption because a closed-form analytical solution of the damper force can be computed when NRHA is employed. Recent shake table experiments of a full-scale 5-story steel frame building equipped with viscous dampers that were conducted at the world's largest shake table around the world (Ooki et al. 2009; Kasai and Matsuda 2014) demonstrated that the consideration of the damper axial stiffness is critical in order to accurately predict both local and global seismic demands of the test structure (Kasai et al. 2007; Kasai and Matsuda 2014). 
This peer-reviewed published paper appears as: Akcelyan, S., Lignos, D. G. and Hikino, T. (2018). "Adaptive Numerical Method Algorithms for Nonlinear Viscous and Bilinear Oil Damper Models Subjected to Dynamic Loading". Soil Dynamics and Earthquake Engineering, Vol. 113, pp. 488-502. DOI: 10.1016/j.soildyn.2018.06.021

54 A blind analysis contest that was conducted to challenge the existing modeling capabilities for steel frame buildings equipped with various types of dampers demonstrated that when the brace and damper axial stiffness is incorporated in nonlinear viscous dampers, it improves the overall prediction accuracy by more than 20\% compared to the experimental data (Yu et al. 2013). Recent studies (Dong et al. 2015, 2018) have shown that the displacement-induced forces and damper force demands may be in phase within a frame building due to the axial stiffness of the respective damper. This has a profound effect on

60 the seismic demands transferred to the steel columns and foundations and should be carefully quantified.

61 Several researchers have proposed ways to account for the stiffening and frequency dependency of viscous dampers and to compute numerically their hysteretic response under harmonic and seismic excitations by employing the Maxwell model (Makris and Constantinou 1991; Constantinou and Symans 1993; Reinhorn et al. 1995; Takahashi and Sekiguchi 2001; Oohara and Kasai 2002; Singh et al. 2003). Typical fixed time-step integration algorithms that have been employed to obtain numerically the viscous damper hysteretic response may require considerably small integration steps to overcome convergence problems (Oohara and Kasai 2002). In particular, numerical convergence may still be a challenge for frame buildings equipped with nonlinear viscous dampers with high axial stiffness and small velocity exponents (Oohara and Kasai 2002). In such cases, a smaller integration time step for the overall analysis is necessary. This reduces the computational efficiency of the analysis of building models with nonlinear

71 viscous dampers. This may also be a fundamental constraint for the optimal seismic design and/or retrofit 72 of frame buildings with nonlinear viscous dampers in which the locations as well as the damper sizes 73 should be explicitly identified as part of the optimization problem (Lavan et al. 2008; Lavan and Avishur 74 2013; Pollini et al. 2017). It is understood that improved integration algorithms should be utilized to 75 reliably obtain the numerical solution of nonlinear viscous damper models.

76 Others have proposed ways to account for the stiffening and frequency dependency of viscous 77 dampers to compute their hysteretic response under harmonic and seismic excitations. For 
This peer-reviewed published paper appears as: Akcelyan, S., Lignos, D. G. and Hikino, T. (2018). "Adaptive Numerical Method Algorithms for Nonlinear Viscous and Bilinear Oil Damper Models Subjected to Dynamic Loading". Soil Dynamics and Earthquake Engineering, Vol. 113, pp. 488-502. DOI: 10.1016/j.soildyn.2018.06.021

instance, Terenzi (1999) has employed the Kelvin-Voigt model, in which $a$ spring is connected parallel to a dashpot. This modeling approach is commonly utilized for solid viscoelastic devices. However, a Maxwell model (i.e., spring connected in series with a dashpot), has been found to be more appropriate to account for both the stiffness and frequency dependency of fluid viscoelastic dampers (Makris and Constantinou 1991; Constantinou and Symans 1993; Reinhorn et al. 1995; Takahashi and Sekiguchi 2001; Oohara and Kasai 2002; Singh et al. 2003). Others (Sivaselvan et al. 2009) have utilized a mixed Lagrangian approach to conduct nonlinear response history analyses of frame structures with linear and nonlinear viscous dampers.

This paper discusses the numerical implementation of an improved adaptive algorithm for the numerical solution of the constitutive equations of nonlinear viscous and bilinear oil damper material models under dynamic loading when the axial stiffness of the dampers is considered as part of the constitutive damper formulation. The efficiency of the proposed algorithms is compared with that of traditional integration schemes that are typically used for the numerical solution of initial value problems. The proposed numerical solution techniques are implemented in an open-source finite element simulation platform and are validated with full-scale tests from nonlinear viscous and bilinear oil dampers subjected to sinusoidal excitations and various loading frequencies. Furthermore, experimental data from a 5-story steel building with the same damper types that was tested at full-scale is utilized to demonstrate the efficiency of the proposed adaptive numerical schemes in predicting global and local engineering demand parameters of frame buildings equipped with supplemental damping devices. Finally, the paper provides tools to aid the preliminary design of steel frame buildings equipped with nonlinear viscous dampers so as analysis iterations with unnecessarily too stiff or too flexible damper models can be eliminated.

\section{Hysteretic Behaviour of Viscous Dampers as Pure Viscous Models}


This peer-reviewed published paper appears as: Akcelyan, S., Lignos, D. G. and Hikino, T. (2018). "Adaptive Numerical Method Algorithms for Nonlinear Viscous and Bilinear Oil Damper Models Subjected to Dynamic Loading". Soil Dynamics and Earthquake Engineering, Vol. 113, pp. 488-502. DOI: 10.1016/j.soildyn.2018.06.021

101 Viscous dampers contain a polymer liquid and its flow through orifices leads to pressure differential 102 across a piston head, which produces the damper force. The design of orifice dictates the relationship 103 between the force and velocity. Thus, the general force-velocity relationship of nonlinear viscous models 104 can be mathematically by Equation (1) (Symans and Constantinou 1998),

$$
F_{d}(t)=C_{d}\left|\dot{u}_{d}(t)\right|^{\alpha} \operatorname{sgn}\left(\dot{u}_{d}(t)\right)
$$

106 in which, $C_{d}$ is the damping coefficient and $\alpha$ is the velocity exponent that characterizes the viscous 107 material; $u_{d}$ is the dashpot displacement ; and sgn represents the signum function. Thus, the peak force $F_{d 0}$ 108 of a viscous damper under a harmonic displacement excitation that is described as $u_{d}(t)=u_{d 0} \sin (\omega t)$, is as 109 follows,

$$
F_{d 0}=C_{d}\left(\omega u_{d 0}\right)^{\alpha}
$$

111 in which, $u_{d 0}$ and $\omega$ are the peak displacement amplitude and the circular frequency of the sinusoidal 112 excitation, respectively. Figure 1 shows the normalized force-velocity and normalized force-displacement 113 relations of nonlinear viscous models with different $\alpha$ values. A typical Bernoullian cylindrical shaped 114 orifice produces forces, which are proportional to the square of the velocity (i.e., $\alpha=2)$. Such dampers are 115 utilized for shock wave absorption. For $\alpha=1$, a viscous damper becomes linear while for $\alpha=0$ the force116 displacement hysteretic relation of a viscous damper becomes rectangular, which is typical for friction 117 models (Pall and Marsh 1982). For seismic design applications of frame buildings the capability of 118 limiting the damper force output under high velocity pulses is often desirable. Therefore for seismic 119 applications, $\alpha$ is often selected such that $\alpha<1$. Because linear viscous dampers produce forces that vary 120 linearly with respect to the velocity demand, large damper forces may be generated under high velocity 121 demands. This introduces uncertainties and conservatism in capacity design of non-dissipative members. 122 In order to overcome this undesirable response, bilinear oil dampers were developed that contain a relief 123 mechanism, which suppresses the force after a certain limit (Ichihasi et al. 2000; Kasai and Nishimura 
This peer-reviewed published paper appears as: Akcelyan, S., Lignos, D. G. and Hikino, T. (2018). "Adaptive Numerical Method Algorithms for Nonlinear Viscous and Bilinear Oil Damper Models Subjected to Dynamic Loading". Soil Dynamics and Earthquake Engineering, Vol. 113, pp. 488-502. DOI: 10.1016/j.soildyn.2018.06.021

2004; Kasai et al. 2004b; Tsuyuki et al. 2004). This creates a bilinear relation between the damper force and velocity as shown in Figure 2a. Thus, the force produced by a bilinear viscous damper can be computed as follows,

$$
F_{d}(t)= \begin{cases}C_{d} \dot{u}_{d}(t), & \left|F_{d}(t)\right| \leq F_{d r} \\ \operatorname{sgn}\left(\dot{u}_{d}(t)\right) F_{d r}+p\left(\dot{u}_{d}(t)-\dot{u}_{d r}\right), & \left|F_{d}(t)\right|>F_{d r}\end{cases}
$$

in which, $p$ is the post relief damping coefficient ratio; $F_{d r}$ and $\dot{u}_{d r}$ are the relief force and velocity of the bilinear oil damper, respectively. The peak force $F_{d 0}$ of a bilinear viscous damper under sinusoidal displacement excitation $u_{d}(t)=u_{d o} \sin (\omega t)$ can be computed as follows,

$$
F_{d 0}=\left(p+\frac{1-p}{\mu_{d}}\right) C_{d} \omega u_{d 0}
$$

the peak damper velocity ratio, $\mu_{d}$ of a bilinear viscous damper, which is defined as the ratio of maximum velocity demand over the damper relief velocity can be computed as follows,

$$
\mu_{d}=\frac{\dot{u}_{d 0}}{\dot{u}_{d r}}=\frac{\omega u_{d 0}}{\dot{u}_{d r}}
$$

Figure $2 \mathrm{~b}$ illustrates the hysteretic behaviour of a bilinear viscous damper under sinusoidal loading for different displacement amplitudes. In this figure, the horizontal axis has been normalized with respect to the peak displacement amplitude. The damper was designed for a peak damper velocity, $\mu_{d}=3$. The postrelief damping coefficient ratio was assumed to be $p=0.1$. The displacement amplitudes were increased in three steps. During the first step, the peak damper velocity was nearly equal to the damper relief velocity; therefore the hysteretic behaviour of the damper was identical to that of a linear viscous damper (Kasai et al. 2004b; Tsuyuki et al. 2004). Once the velocity demand exceeds the damper relief velocity, the relief mechanism is activated and the damping coefficient, $C_{d}$, suddenly drops as shown in Figure $2 \mathrm{~b}$.

\section{Hysteretic Behaviour of Viscous Dampers as Maxwell Models}


This peer-reviewed published paper appears as: Akcelyan, S., Lignos, D. G. and Hikino, T. (2018). "Adaptive Numerical Method Algorithms for Nonlinear Viscous and Bilinear Oil Damper Models Subjected to Dynamic Loading". Soil Dynamics and Earthquake Engineering, Vol. 113, pp. 488-502. DOI: 10.1016/j.soildyn.2018.06.021

145 Prior experimental findings suggest that the hysteretic behaviour of a viscous damper is dependent on its 146 axial internal stiffness $K_{d}$, as well as the frequency characteristics of the external applied force

147 (Constantinou and Symans 1993). Typically, $K_{d}$ can be obtained empirically from experimental data as 148 discussed in Makris and Constantinou (1991) and Kasai et al. (2004a; 2004b). Referring to Figure 3a,

149 viscous dampers in frame buildings are typically installed with supporting braces that consist of several 150 components (e.g., steel braces, clevises, brackets and gusset plates). These components provide additional 151 axial flexibility to the damper and affect its hysteretic behaviour under dynamic loading. The axial 152 flexibility of a viscous damper can be further decomposed into its various components as shown 153 schematically in Figure $3 \mathrm{~b}$. In this figure, $K_{b}, K_{c l}, K_{\text {gus }}$ are the stiffness contributions of the steel brace, 154 clevis-brackets and gusset plates, respectively. The gap due to the fabrication tolerance of the damper 155 clevis is noted as $G_{c l}$ in the same figure. To this end, the Maxwell model (Maxwell 1867) has been found to represent well both the axial stiffness and frequency dependency of a viscous damper under dynamic 157 loading (Makris and Constantinou 1991; Constantinou and Symans 1993; Singh et al. 2003). In this case, 158 a nonlinear dashpot and a linear spring are connected in series as illustrated in Figure $3 \mathrm{c}$. The axial 159 stiffness of the damper portion, $K_{d}$, and that of the various supporting components (see Figure $3 \mathrm{~b}$ ) can be 160 represented by an equivalent axial stiffness, $K_{s}$, as follows,

$$
\frac{1}{K_{s}}=\frac{1}{K_{d}}+\frac{1}{K_{b}}+\frac{2}{K_{c l}}+\frac{2}{K_{\text {gus }}}
$$

162 The force, $F_{d}$ at the nonlinear dashpot and spring $\left(F_{s}\right)$ are equal; therefore, the constitutive rules within a 163 Maxwell model can be written as follows,

$$
u_{m}(t)=u_{s}(t)+u_{d}(t)
$$

$$
\dot{u}_{m}(t)=\dot{u}_{s}(t)+\dot{u}_{d}(t)
$$


This peer-reviewed published paper appears as: Akcelyan, S., Lignos, D. G. and Hikino, T. (2018). "Adaptive Numerical Method Algorithms for Nonlinear Viscous and Bilinear Oil Damper Models Subjected to Dynamic Loading". Soil Dynamics and Earthquake Engineering, Vol. 113, pp. 488-502. DOI: 10.1016/j.soildyn.2018.06.021

167 in which, $u_{m}, u_{d}$ and $u_{s}$ are the total, dashpot and spring displacements, respectively (see Figure 3c). The 168 constitutive equation that describes the force and total velocity relation within a Maxwell model can be 169 obtained if Equations (7) and (8) are substituted into Equation (9). For a nonlinear viscous damper this 170 equation is as follows,

$$
F_{d}^{\prime}(t)=\left(\dot{u}_{m}(t)-\operatorname{sgn}\left(F_{d}(t)\right)\left(\frac{\left|F_{d}(t)\right|}{C_{d}}\right)^{1 / \alpha}\right) K_{s}, \quad F_{d}\left(t_{0}\right)=F_{d 0}
$$

for a bilinear oil damper, the following equations hold true,

$$
F_{d}^{\prime}(t)=\left\{\begin{array}{ll}
\left(\dot{u}_{m}(t)-\frac{F_{d}(t)}{C_{d}}\right) K_{s}, & \left|F_{d}(t)\right| \leq F_{d r} \\
\left(\dot{u}_{m}(t)-\frac{\operatorname{sgn}\left(F_{d}(t)\right)(p-1) F_{r}+F_{d}(t)}{p C_{d}}\right) K_{s}, & \left|F_{d}(t)\right|>F_{d r}
\end{array}, \quad F_{d}\left(t_{0}\right)=F_{d 0}\right.
$$

Equations (10) and (11) are first order ordinary differential equations that can only be solved numerically in the case of a random vibration input loading.

\section{Numerical Solution for Nonlinear Viscous and Bilinear Oil Dampers}

This section discusses a numerical solution scheme for Equations (10) and (11). For this reason, both equations are treated as a general initial value problem that is described by Equation (12) as follows,

$$
y^{\prime}=f\left(t_{n}, y_{n}\right), \quad y\left(t_{0}\right)=y_{0}
$$

Oohara and Kasai (2002) implemented the classical $4^{\text {th }}$ order Runge-Kutta (RK4) explicit iterative method (Kutta 1901; Butcher 1996) to solve Equation (12) for nonlinear viscous dampers. They stated that the classical RK4 method requires very small integration time steps, $h$, for large $K_{s}$ values. For NRHA of frame buildings under earthquake excitations, the maximum value of $h$ is limited by the overall analysis time step $d t_{a}$ of the integration algorithm that is employed for the numerical solution of the equation of motion; while $d t_{a}$ should be selected at most equal to the time step of the input ground motion $d t$ 
This peer-reviewed published paper appears as: Akcelyan, S., Lignos, D. G. and Hikino, T. (2018). "Adaptive Numerical Method Algorithms for Nonlinear Viscous and Bilinear Oil Damper Models Subjected to Dynamic Loading". Soil Dynamics and Earthquake Engineering, Vol. 113, pp. 488-502. DOI: 10.1016/j.soildyn.2018.06.021

187 depending on the selected integration algorithm to conduct the NRHA; the ratio of $d t / d t_{a}$ should be an 188 integer. Typical sampling time steps of recorded ground motions vary between 0.005-0.02 sec. However, 189 for a large axial damper stiffness, $K_{s}$ a much smaller step $h$ should be considered for the utilization of the 190 RK4 iterative method and subsequently the overall NRHA time step $d t_{a}$ should be further decreased. This 191 could be computationally expensive particularly in 3-dimensional nonlinear response history analysis of 192 frame structures.

193 Alternatively, adaptive solution algorithms may be used. In this section, we utilize the Dormand-Prince 194 (DP54) explicit iterative method (Dormand and Prince 1980) as the basis to solve numerically Equation 195 (12). The solution of this equation is tested with the absolute error predicted between $4^{\text {th }}$ and $5^{\text {th }}$ order solutions. The $4^{\text {th }}$ order solution and the associated absolute error according to the DP54 iterative method for Equation (12) are computed based on Equations (13) and (14), respectively, as follows,

$$
\begin{gathered}
y_{n+1}=y_{n}+\frac{35}{384} k_{1}+\frac{500}{1113} k_{3}+\frac{125}{192} k_{4}-\frac{2187}{6784} k_{5}+\frac{11}{84} k_{6} \\
\varepsilon_{n+1}=\left|\frac{71}{57600} k_{1}-\frac{71}{16695} k_{3}+\frac{71}{1920} k_{4}-\frac{17253}{339200} k_{5}+\frac{22}{525} k_{6}-\frac{1}{40} k_{7}\right|
\end{gathered}
$$
$\varepsilon_{n+1}$ is the absolute error of the numerical solution in the current step. Note that the term $k_{2}$ should not appear in Equations (13) and (14) as summarized in Hairer et al. (1993). From Equations (15) to (21), the DP54 explicit iterative method uses six function evaluations in order to calculate the $4^{\text {th }}$ and $5^{\text {th }}$ order accurate numerical solutions for Equation (14). These function evaluations are computed as follows,

$$
k_{1}=h f\left(t_{n}, y_{n}\right)
$$

$$
k_{2}=h f\left(t_{n}+\frac{1}{5} h, y_{n}+\frac{1}{5} k_{1}\right)
$$


This peer-reviewed published paper appears as: Akcelyan, S., Lignos, D. G. and Hikino, T. (2018). "Adaptive Numerical Method Algorithms for Nonlinear Viscous and Bilinear Oil Damper Models Subjected to Dynamic Loading". Soil Dynamics and Earthquake Engineering, Vol. 113, pp. 488-502. DOI: 10.1016/j.soildyn.2018.06.021

$$
\begin{gathered}
k_{4}=h f\left(t_{n}+\frac{4}{5} h, y_{n}+\frac{44}{45} k_{1}-\frac{56}{15} k_{2}+\frac{32}{9} k_{3}\right) \\
k_{5}=h f\left(t_{n}+\frac{8}{9} h, y_{n}+\frac{19372}{6561} k_{1}-\frac{25360}{2187} k_{2}+\frac{64448}{6561} k_{3}-\frac{212}{729} k_{4}\right) \\
k_{6}=h f\left(t_{n}+h, y_{n}+\frac{9017}{3168} k_{1}-\frac{355}{33} k_{2}+\frac{46732}{5247} k_{3}+\frac{49}{176} k_{4}-\frac{5103}{18656} k_{5}\right) \\
k_{7}=h f\left(t_{n}+h, y_{n+1}\right)
\end{gathered}
$$

212 Figure 4 shows a flowchart of a single solution step, $i+1$, within a response history analysis of a nonlinear

213 viscous damper. In order to obtain the damper force for the current step, $F_{d, i+1}$, the required input 214 parameters from the overall response history analysis are the integration time step $d t_{a}$ of the employed integrator for response history analysis (i.e., different than the one employed to obtain the damper force), the velocity of the current and previous steps, $\dot{u}_{i+l}, \dot{u}_{i}$, respectively, and the damper force, $F_{d, i}$ from the

217 previous step, $i$ of the response history analysis. The velocity $u$ represents the velocity $\dot{u}_{\mathrm{m}}$ of the Maxwell model. During the initial iteration to compute the damper force, the numerical integration step, $h$ of the DP54 method is set equal to $d t_{a}$. If the relative error $\varepsilon_{r e l}$ is larger than a pre-defined relative tolerance (noted as "RelTol") or if the absolute error is larger than the absolute tolerance (noted as "AbsTol"), the solution algorithm reduces its time step $h$ by half (see Eq. (23)) using a half-step coefficient, $s$ (see Eq. (24)) till Equation (22) is satisfied. In this case, the velocity $\dot{u}_{n+1}$ at the current solution sub-step, which is required from the DP54 iterative method, should be interpolated linearly between $\dot{u}_{i}$ and $\dot{u}_{i+1}$ at the corresponding sub-step. Therefore, the computation of the acceleration $\ddot{u}_{\mathrm{i}+1}$ at the current solution step is needed. Similarly, velocity values within the function evaluations of DP54 iterative method should be linearly interpolated between $\dot{u}_{n}$ and $\dot{u}_{n+1}$ at the corresponding time increments. As the sum of half-step coefficients $S_{t o t}$ becomes equal to unity, we can obtain the damper force at the current solution step, $F_{d, i+1}$. 
This peer-reviewed published paper appears as: Akcelyan, S., Lignos, D. G. and Hikino, T. (2018). "Adaptive Numerical Method Algorithms for Nonlinear Viscous and Bilinear Oil Damper Models Subjected to Dynamic Loading". Soil Dynamics and Earthquake Engineering, Vol. 113, pp. 488-502. DOI: 10.1016/j.soildyn.2018.06.021

size $h_{\min }$. This can simply be done by defining a maximum number of iterations, $N_{i t, \max }$, for the half step coefficient $s$ as shown in Equation (24).

$$
\varepsilon_{r e l, n+1} \leq \text { RelTol or } \varepsilon_{n+1} \leq \text { AbsTol }
$$

In order to investigate the effectiveness of the adaptive time step DP54 iterative method on the numerical solution of the force for nonlinear viscous dampers under a sinusoidal displacement excitations, Figure 5 illustrates the force-displacement relation of nonlinear viscous dampers with varying velocity exponents, $\alpha(\alpha$ varies from 0.01 to 2$)$ and normalized damper axial stiffnesses, $k_{s}$ (i.e., $k_{s}$ varies from 0.1 to 1000 ). The sinusoidal displacement that represents the external loading is $u_{m 0} \sin (\omega t)$ in which $u_{m 0}$ and $\omega$ are the peak displacement amplitude and the angular frequency $(\omega=2 \pi f)$ of the external loading, respectively. In this case, $u_{m o}=1$ and $f=1 \mathrm{~Hz}$. Referring to Figs. 5 to 8 , a $1.0 \mathrm{~Hz}$ frequency is selected just for the sake of comparisons between computed solutions and experimental results. This frequency is within a typical frequency range of harmonic input excitations that are used for experimental testing of supplemental damping devices (Kasai et al. 2004b). The authors have validated the computed solutions with other meaningful frequency ranges that reflect those typically seen in seismic excitations relative to the employed supplemental damping device characteristics. The overall time step $d t_{a}$ of the external loading was selected to be $d t_{a}=0.01 \mathrm{sec}$. The nonlinear viscous damper was designed such that if $k_{s}$ is neglected then the peak damper force, $F_{d 0}$ becomes unity. Thus, $F_{d 0}$ can be computed from Equation (25) (i.e., pure viscous dashpot) and therefore, $u_{d 0}=u_{m 0}$. In this case, the normalized damper stiffness $k_{s}$ can be obtained from Equation (26). A relative tolerance RelTol $=10^{-6}$ and an absolute tolerance AbsTol $=10^{-10}$ are selected herein. The selected threshold for the relative and absolute tolerances is deemed to be small enough for the reliable computation of the numerical solutions of Equations (10) and (11). The selected 
This peer-reviewed published paper appears as: Akcelyan, S., Lignos, D. G. and Hikino, T. (2018). "Adaptive Numerical Method Algorithms for Nonlinear Viscous and Bilinear Oil Damper Models Subjected to Dynamic Loading". Soil Dynamics and Earthquake Engineering, Vol. 113, pp. 488-502. DOI: 10.1016/j.soildyn.2018.06.021

252 values are consistent with prior work on the numerical solution of initial value problems (Griffiths and Higham 2010). More strict convergence criteria could be possibly considered; although the sufficiency of the numerical solution would marginally change, its efficiency would be less given the higher computational cost.

$$
F_{d 0}=C_{d}\left(\omega u_{m 0}\right)^{\alpha}
$$

$$
k_{s}=K_{s} \frac{u_{m 0}}{F_{d 0}}
$$

The number of iterations, $N_{\text {it }}$ required for the half step coefficient are reported for each case in Figure 5. From this figure, when $k_{s}$ increases the required number of iterations in order to achieve convergence based on the pre-defined tolerances also increases. From the same figure, the damper exponent $\alpha$ variation

261 has a relatively small influence on the required number of iterations for numerical convergence. The only 262 exception is for $\alpha=2$, in which a relatively large number of iterations is required to satisfy the pre263 defined convergence tolerances (see Figure 5). This is due to the fact that for $\alpha=2$ the absolute tolerance 264 becomes the critical condition to minimize the error in the damper force prediction, while for all other $\alpha$ 265 values the relative tolerance limits $N_{\text {it. }}$ From Figure 5, it is evident that $k_{s}$ strongly affects the peak damper 266 forces as well as the damper hysteretic shape. These issues are further investigated later on as part of this 267 paper.

268 In order to illustrate the accuracy of the adaptive integration algorithm for obtaining the hysteretic 269 response of nonlinear viscous dampers compared to traditional iterative numerical methods that have been 270 previously employed, Figure 6 illustrates the force-displacement relations for the same nonlinear viscous 271 dampers that were analyzed in Figure 5 when the classical $4^{\text {th }}$ order RK4 iterative method is employed.

272 Referring to Figure 6, it is evident that when the RK4 iterative method is employed and for $d t_{a}=0.01 \mathrm{sec}$ 273 it is not possible to obtain the numerical solution of Equation (10) if $k_{s}>10$. Notably, numerical 
This peer-reviewed published paper appears as: Akcelyan, S., Lignos, D. G. and Hikino, T. (2018). "Adaptive Numerical Method Algorithms for Nonlinear Viscous and Bilinear Oil Damper Models Subjected to Dynamic Loading". Soil Dynamics and Earthquake Engineering, Vol. 113, pp. 488-502. DOI: 10.1016/j.soildyn.2018.06.021

274

275

276

277

convergence is achieved for only three $\alpha$ values (i.e., $\alpha=0.5,1.0$ and 2.0). In order to obtain a stable numerical solution even in these cases an integration step $d t_{a}=0.00005 \mathrm{sec}$ must be selected.

The adaptive DP54 iterative method can be also implemented for the numerical solution of bilinear oil dampers. In this case, Equation (11) is solved numerically. Note that when $p=0$ (i.e., constant damper force after relief), $F_{d}^{\prime}(\mathrm{t})$ in Equation (11) becomes infinite; therefore the damper force, $F_{d, i+l}$ in this case should be directly equal to $F_{d r}$. Alternatively, we can compute the damper force $F_{d, i+1}$ through a finite difference approximation of Eq. (11) as follows,

$$
F_{d}(t)=F_{d, i+1}
$$

After substituting Equations (27) to (29) into Equation (11), Equation (30) is obtained. First, $F_{d, i+l}$ shall be computed through Equation (30) by assuming that the oil damper is linear (i.e., $\left|F_{d, i+1}\right| \leq F_{d r}$ ). If the computed damper force $\left|F_{d, i+1}\right|>F_{d r}$, then $F_{d, i+1}$ shall be recomputed using the sign value, $\operatorname{sgn}\left(F_{d, i+1}\right)$ of the initially computed linear oil damper force prediction.

$$
F_{d, i+1}= \begin{cases}\frac{F_{d, i}+\dot{u}_{m, i+1} K_{s} h}{1+K_{s} h / C_{d}}, & \left|F_{d, i+1}\right| \leq F_{d r} \\ F_{d, i}+\dot{u}_{m, i+1} K_{s} h+\left[\operatorname{sgn}\left(F_{d, i+1}\right)(p-1) F_{d r} K_{s} h\right] /\left(p C_{d}\right) & , \\ 1+K_{s} h / C_{d} & \left|F_{d, i+1}\right|>F_{d r} \text { and } p \neq 0 \\ \operatorname{sgn}\left(F_{d, i+1}\right), & \left|F_{d, i+1}\right|>F_{d r} \text { and } p=0\end{cases}
$$

Kasai et al. (2004b) recommended that in order to compute the bilinear oil damper force with a high precision, smaller integration steps should be employed. In order to be compatible with the adaptive DP54 iterative method, the error of the numerical solution in this case is defined by subtracting the solution obtained in the current iteration from that of an additional step. For this reason, two numerical solutions 
This peer-reviewed published paper appears as: Akcelyan, S., Lignos, D. G. and Hikino, T. (2018). "Adaptive Numerical Method Algorithms for Nonlinear Viscous and Bilinear Oil Damper Models Subjected to Dynamic Loading". Soil Dynamics and Earthquake Engineering, Vol. 113, pp. 488-502. DOI: 10.1016/j.soildyn.2018.06.021

are obtained per iteration, one computed with a time step $h_{1}$ and another one with $h_{2}$ as shown in Equation

(31). Similar to the adaptive DP54 iterative method, for each iteration the integration time step is reduced

by half, until the absolute error or the absolute relative error becomes smaller than the predefined tolerances, based on Equation (22).

$$
h_{1}=s \cdot d t_{a}, \quad h_{2}=s /(s+1) \cdot d t_{a}
$$

In order to compare the adaptive DP54 iterative method with the proposed adaptive numerical integration method (NI) discussed herein for the case of bilinear oil dampers, the force-displacement relations for oil dampers under a sinusoidal external loading with $u_{m o}=1$ and $\mathrm{f}=1 \mathrm{~Hz}$ are computed in Figures 7 and 8 . The oil dampers are designed such that their peak force, $F_{d 0}$, becomes unity when the damper axial flexibility is neglected. For oil dampers, $F_{d 0}$ can be computed based on Equation (32). Two cases are analyzed. In the first case, the peak damper velocity ratios are fixed (i.e., $\mu_{m}=2$ ) and $p$ varies from 0 to 1.0 (see Figure 7). In the second case, the $p$ value is fixed (i.e., $p=0.05$ ) and $\mu_{m}$ varies from 1 to 20 (see Figure 8). For both cases, the normalized damper axial stiffness, $k_{s}$ varies from 0.1 to 1000 . The relative and absolute tolerances are set equal to RelTol $=10^{-6}$ and AbsTol $=10^{-10}$, respectively.

$$
\begin{gathered}
F_{d 0}=\left(p+\frac{1-p}{\mu_{m}}\right) C_{d} \omega u_{m 0} \\
\mu_{m}=\frac{\omega u_{m 0}}{\dot{u}_{d r}}
\end{gathered}
$$

Figure 7 illustrates the computed hysteretic behaviour of oil dampers with varying $p$ and $k_{s}$ values based

310 on the adaptive DP54 and finite difference approximation methods. In the same figure we have 311 superimposed the number of iterations, $N_{\text {it }}$ required for the half step coefficient based on both iterative 312 methods. From Figure 7 it is concluded that for large $k_{s}$ values (i.e., $k_{s} \geq 100$ ) a small integration time step 313 is required when the adaptive DP54 method is employed; however, this is not the case when the 314 alternative proposed integration scheme is employed. Therefore, for oil dampers that utilize $k_{s} \geq 100$ the 
This peer-reviewed published paper appears as: Akcelyan, S., Lignos, D. G. and Hikino, T. (2018). "Adaptive Numerical Method Algorithms for Nonlinear Viscous and Bilinear Oil Damper Models Subjected to Dynamic Loading". Soil Dynamics and Earthquake Engineering, Vol. 113, pp. 488-502. DOI: 10.1016/j.soildyn.2018.06.021

alternative numerical integration method is able to provide the same solution accuracy with the adaptive DP54 iterative method with a smaller number of iterations. For flexible bilinear oil dampers (i.e.,

$\left.317 k_{s}<100\right)$ the adaptive DP54 iterative method typically satisfies the pre-defined tolerance criteria with just 318 a single iteration (see Figure 7). Similar conclusions hold true when $p$ is fixed (i.e., $p=0.05$ ) and the peak 319 damper velocity ratio, $\mu_{m}$ varies (see Figure 8).

\section{Sensitivity of Viscous Damper Behaviour to the Damper Axial Stiffness}

322 This section investigates the effect of the axial stiffness, $K_{s}$ due to viscoelasticity of a viscous damper on 323 its hysteretic behaviour and dynamic stiffnesses based on the proposed adaptive numerical method 324 discussed above. In particular, a sensitivity study is conducted in order to quantify the effect of $K_{s}$ on the 325 reduction factor of the damper energy dissipation, $e_{K}$; the damper peak force, $F_{d o}$; the damper storage 326 stiffness, $K_{m, s t}$; and the damper loss stiffness, $K_{m, l}$. A harmonic vibration is assumed for this purpose. A 327 sinusoidal displacement that represents the external loading is applied with $u_{m o}=1$ and $f=1 \mathrm{~Hz}$. The 328 evaluation is conducted in a normalized manner. In particular, similarly with the normalized stiffness $k_{s}$ 329 (see Equation (26)), the normalized storage and loss stiffnesses $k_{\mathrm{m}, \mathrm{st}}$ and $k_{\mathrm{m}, \mathrm{l}}$, respectively, can be obtained 330 according to Equation (26). Figure 9 illustrates the graphical definition of these phenomena as well as the 331 dynamic stiffnesses (see Figure 9c). The reduction factor of the damper energy dissipation, $e_{K}$ is obtained 332 by first computing the area under the corresponding damper hysteresis numerically and then dividing it 333 into the energy produced by the pure viscous model under the same loading conditions. The energy 334 dissipated by nonlinear and bilinear viscous models can be directly computed according to Constantinou 335 and Symans (1993) and Kasai and Nishimura (2004), respectively. The normalized peak damper force $f_{m}$ 336 is obtained by dividing the peak damper force into the peak force of a pure viscous model, which can be 337 calculated, based on Equations (25) and (32) for nonlinear and bilinear viscous models, respectively.

338 Nonlinear viscous dampers are employed with the utilization of the Maxwell model in order to facilitate 
This peer-reviewed published paper appears as: Akcelyan, S., Lignos, D. G. and Hikino, T. (2018). "Adaptive Numerical Method Algorithms for Nonlinear Viscous and Bilinear Oil Damper Models Subjected to Dynamic Loading". Soil Dynamics and Earthquake Engineering, Vol. 113, pp. 488-502. DOI: 10.1016/j.soildyn.2018.06.021

the discussion in the next paragraph. The observations below are general and can be applied to bilinear oil dampers not discussed herein due to brevity.

341 Figure 10 illustrates the variation of $e_{K}, f_{m}, k_{\mathrm{m}, \mathrm{st}}$ and $k_{\mathrm{m}, 1}$ (values are normalized as discussed earlier and 342 range between 0 to 1 ) with respect to the nonlinear viscous damper normalized stiffness $k_{s}$ for a wide 343 range of $\alpha$ values. From Figure 10, the following observations hold true,

- The change in $e_{K}$ is relatively large for small $\alpha$ values (see Figure 10a). This is attributed to the fact that the smaller the exponent $\alpha$, the more stable the damper force becomes with the increase of velocity (see Figure 1a). Therefore, a decrease in external total displacement (i.e. $k_{s}$ ) would mainly affect the dashpot displacement and not that of the spring because the spring force remains relatively constant and the spring displacement is proportional to its force. For instance, when $\alpha=0$, for $k_{s}<1$ the damper hysteretic energy diminishes. For $\alpha=0$ (i.e., friction dampers) and $\alpha=1$ (i.e., linear dampers) the reduction factor of the nonlinear viscous damper can be directly computed based on the following equation (Constantinou et al. 1998; Kasai et al. 2003),

$$
e_{K, \alpha=0}=\frac{k_{s}-1}{k_{s}} ; \quad e_{K, \alpha=1}=\frac{k_{s}^{2}}{1+k_{s}^{2}}
$$

- From Figure $10 \mathrm{~b}$ a decrease in $k_{s}$ has a larger impact on the normalized peak forces $\left(f_{m}\right)$ of a damper with large exponent $\alpha$ (e.g., $\alpha=1$ ). Similarly, this is attributed to the fact that the damper force is relatively sensitive to the velocity variation once $\alpha$ becomes large. Therefore, a reduction in the dashpot displacement due to the axial flexibility causes relatively large force reductions

$$
f_{m, \alpha=0}=k_{s} ; \quad f_{m, \alpha=1}=\frac{k_{s}}{\sqrt{1+k_{s}^{2}}}
$$


This peer-reviewed published paper appears as: Akcelyan, S., Lignos, D. G. and Hikino, T. (2018). "Adaptive Numerical Method Algorithms for Nonlinear Viscous and Bilinear Oil Damper Models Subjected to Dynamic Loading". Soil Dynamics and Earthquake Engineering, Vol. 113, pp. 488-502. DOI: 10.1016/j.soildyn.2018.06.021

- The normalized storage stiffness $k_{m, s t}$ is large for small $\alpha$ values; $k_{m, s t}$ becomes maximum when $k_{s}=1$ (see Figure 10c). This implies that although the inclination angle of the damper hysteresis is small for $k_{s}<1$ (see Figure 5), the $k_{m, s t}$ is relatively small due to fact that the normalized peak forces, $f_{m}$ significantly decrease for $k_{s}<1$ as shown in Figure $10 \mathrm{~b}$. For $k_{s}>1$ the $k_{m, s t}$ reduces due to the changing shape of the damper hysteresis. For large $k_{s}$ values the damper hysteresis becomes similar to that of a pure viscous model, which has no storage stiffness. For friction and linear dampers the normalized storage stiffness can be computed as follows,

$$
k_{m, s t, \alpha=0}=k_{s} ; \quad k_{m, s t, \alpha=1}=\frac{k_{s}}{1+k_{s}^{2}}
$$

- From Figure 10d the normalized loss stiffness, $k_{m, l}$ increases with the increase of $k_{s}$. Under the same loading conditions, a pure viscous model would have a normalized loss stiffness $k_{m, l}=1$, because the maximum force occurs at zero displacement; thus the larger the $k_{s}$, the larger the $k_{m, l}$ becomes. Note that Equation (37) can be employed to compute the normalized loss stiffness for friction and linear dampers,

$$
k_{m, l, \alpha=0}=k_{s}-1 ; \quad k_{m, l, \alpha=1}=\frac{k_{s}^{2}}{1+k_{s}^{2}}
$$

Figure 10 can facilitate the design and modeling of the damper stiffness. For instance, Figure 10a suggests that if the damper has a normalized stiffness $\mathrm{k}_{\mathrm{s}}>100$, it is practically a pure viscous model, while for $\mathrm{k}_{\mathrm{s}}=10$ the energy dissipation is about $90 \%$ of that of a viscous model for a low velocity exponent. If $\mathrm{k}_{\mathrm{s}}<$

37710 , the loss in energy dissipation increases dramatically. When $\alpha \approx 0$ the damper hysteretic energy 378 diminishes for $\mathrm{k}_{\mathrm{s}}<1$. These graphs can be utilized to accelerate the preliminary evaluation procedures 379 within a building model. If the damper stiffness properties are unknown, Figure 10 can be used to easily 380 assign a damper stiffness, that is computationally efficient (not too stiff) and at the same time reasonably 381 conservative (i.e. not too flexible) for the evaluation of a building's engineering demand parameters. This 
This peer-reviewed published paper appears as: Akcelyan, S., Lignos, D. G. and Hikino, T. (2018). "Adaptive Numerical Method Algorithms for Nonlinear Viscous and Bilinear Oil Damper Models Subjected to Dynamic Loading". Soil Dynamics and Earthquake Engineering, Vol. 113, pp. 488-502. DOI: 10.1016/j.soildyn.2018.06.021

should aid eliminating analysis iterations with unnecessarily too stiff or too flexible damper models. Note that, an estimation of the building's fundamental frequency and peak damper displacement $\left(\mathrm{u}_{\mathrm{m} 0}\right)$ is sufficient to compute the required damper stiffness that satisfies the selected $\mathrm{k}_{\mathrm{s}}$ (see Eq. 26). Similar expressions can be derived for bilinear oil dampers.

\section{Experimental Validation}

This section discusses the validation of the proposed adaptive integration techniques for the numerical models of nonlinear viscous and bilinear oil dampers. The validation is conducted with damper component experiments conducted in prior studies. System-level experimental data from a full-scale shake table test of a 5-story steel frame building with nonlinear viscous and bilinear oil dampers are also utilized.

\subsection{Component Level Validation}

Component level experiments for both nonlinear viscous and oil dampers are adopted from earlier experimental studies (Kasai et al. 2004b; Ooki et al. 2009; Hikino 2012). The nonlinear viscous damper that was tested had a viscous coefficient, $C_{d}=196 \mathrm{KN} /(\mathrm{mm} / \mathrm{s})^{0.38}$, axial stiffness, $K_{d}=438 \mathrm{KN} / \mathrm{mm}$ and a damper exponent, $\alpha=0.38$. The nonlinear viscous damper was subjected to sinusoidal loading with increasing displacement amplitudes and loading frequencies of $0.5 \mathrm{~Hz}$ and $2 \mathrm{~Hz}$, respectively. Figure 11 illustrates the measured hysteretic response of the nonlinear viscous damper in terms of its forcedisplacement relation for the two loading frequencies of interest. In the same figure, we have superimposed the computed hysteretic response of the nonlinear viscous damper based on a Maxwell model. For the numerical solution of the constitutive equation of the Maxwell model with the proposed adaptive numerical technique an integration step of $0.01 \mathrm{sec}$ is adopted. The adaptive DP54 method required 3 iterations (i.e. $h=0.00125 \mathrm{sec}$ ) to satisfy the pre-defined convergence criteria (i.e., $10^{-6}$ and $10^{-}$ 
This peer-reviewed published paper appears as: Akcelyan, S., Lignos, D. G. and Hikino, T. (2018). "Adaptive Numerical Method Algorithms for Nonlinear Viscous and Bilinear Oil Damper Models Subjected to Dynamic Loading". Soil Dynamics and Earthquake Engineering, Vol. 113, pp. 488-502. DOI: 10.1016/j.soildyn.2018.06.021

${ }^{10}$ for the relative and absolute tolerances, respectively). From Figure 11, the average absolute relative error of the predicted positive and negative peak damper forces per loading cycle versus the measured ones is $9 \%$ and $6 \%$ for 0.5 and $2.0 \mathrm{~Hz}$, respectively. This suggests that the proposed numerical model for nonlinear viscous dampers represents well the experimental data regardless of the employed loading 410 frequency.

411 Similarly, for bilinear oil dampers the experimental data from Kasai et al. (2004b) is utilized. In this case, 412 the oil damper that was tested dynamically at full-scale had an initial damper coefficient, $413 C_{d}=24.5 \mathrm{KN} /(\mathrm{mm} / \mathrm{s})$, an axial stiffness, $K_{d}=392.3 \mathrm{KN} / \mathrm{mm}$, a relief velocity, $V_{r}=32 \mathrm{~mm} / \mathrm{s}$, and a postrelief coefficient ratio, $p=0.068$ (Takahashi and Sekiguchi 2001). The oil damper was subjected to sinusoidal loading with increasing displacement amplitude of 1,5 and $15 \mathrm{~mm}$ and loading frequencies of $0.25 \mathrm{~Hz}$ and $1 \mathrm{~Hz}$. Figure 12 illustrates the measured hysteretic response of the bilinear oil damper for the 417 two loading frequencies of interest. From Figure 3.12a, at $0.25 \mathrm{~Hz}$ the relief valve of the oil damper was not activated; therefore, the damper response was linear. However, at $1 \mathrm{~Hz}$ and during the last loading cycle (i.e., displacement amplitude of $15 \mathrm{~mm}$ ) the damper relief velocity was exceeded. Thus, a bilinear force-velocity relation was measured as shown in Figure 12b. In the same figure we have superimposed

421 the computed hysteretic response of the same damper. The integration step of the proposed adaptive 422 numerical technique that was employed was $0.01 \mathrm{sec}$. The adaptive DP54 method required 5 iterations 423 (i.e. $h=0.0003125 \mathrm{sec}$ ) to satisfy the pre-defined convergence criteria (i.e., $10^{-6}$ and $10^{-10}$ for the relative 424 and absolute tolerances, respectively). Referring to Figure 12, the computed hysteretic response of the oil 425 damper is nearly identical with the one obtained from the experimental data regardless of the loading 426 frequency. This is also indicated from the average absolute error of positive and negative peak damper 427 forces per loading cycle that was $5 \%$ and $3 \%$ for $0.25 \mathrm{~Hz}$ and $1 \mathrm{~Hz}$, respectively. 
This peer-reviewed published paper appears as: Akcelyan, S., Lignos, D. G. and Hikino, T. (2018). "Adaptive Numerical Method Algorithms for Nonlinear Viscous and Bilinear Oil Damper Models Subjected to Dynamic Loading". Soil Dynamics and Earthquake Engineering, Vol. 113, pp. 488-502. DOI: 10.1016/j.soildyn.2018.06.021

430 This section discusses the implementation of the proposed adaptive integration techniques for simulating 431 the hysteretic response of nonlinear viscous and bilinear oil dampers based on the utilization of full-scale 432 shake table experiments of a 5-story steel frame building that was tested at the world's largest shake table 433 at E-Defense in Japan (Ohtani et al. 2004; Kasai et al. 2008; Kasai et al. 2010; Hikino 2012; Kasai and 434 Matsuda 2014). The test structure was equipped various types of dampers including nonlinear viscous and 435 bilinear oil dampers (Ooki et al. 2009; Kasai et al. 2010; Hikino 2012). The employed numerical models 436 including the adaptive integration techniques (noted as "ViscousDamper" and "BilinearOilDamper") 437 discussed in this paper have been implemented in an open-source finite element simulation platform for 438 nonlinear response history analysis of 2- and 3-Dimensional frame buildings under earthquake excitations 439 [so called: Open System for Earthquake Engineering Simulation (OpenSees), (McKenna 1997)]. These 440 models including their documentation are publically available (BilinearOilDamper 2015; ViscousDamper $4412015)$.

442 Figure 13a shows the test structure after the installation on the E-Defense shake table. The test structure 443 plan view was $10 \times 12 \mathrm{~m}$ as (see Figure $13 \mathrm{~b}$ ). Its total height was $15.85 \mathrm{~m}$ and its overall weight was $4444730 \mathrm{KN}$. Detailed information regarding the test structure is reported extensively elsewhere (Ooki et al. 445 2009; Kasai et al. 2010; Kasai and Matsuda 2014). Due to brevity, the reader is referred to the 446 aforementioned studies.

447 Twelve dampers were installed in the test structure in total (four in the Y-loading direction; eight in the 448 X-loading direction) as shown in Figures 13c and 13d. Table 1 provides the various properties of the 449 nonlinear viscous and oil dampers based on damper component tests prior to the shake table experiments.

450 In summary, Table 1 includes the damping coefficients, $C_{d}$, the stiffness properties (i.e., damper portion, $451 K_{d}$ and total stiffness $K_{s}$ ) of the corresponding dampers installed in the test structure. The velocity 452 exponent, $\alpha$, of the nonlinear viscous dampers was found to be, $\alpha=0.38$. The relief velocity, $V_{r}$ and post 
This peer-reviewed published paper appears as: Akcelyan, S., Lignos, D. G. and Hikino, T. (2018). "Adaptive Numerical Method Algorithms for Nonlinear Viscous and Bilinear Oil Damper Models Subjected to Dynamic Loading". Soil Dynamics and Earthquake Engineering, Vol. 113, pp. 488-502. DOI: 10.1016/j.soildyn.2018.06.021

453 relief damping coefficient ratio, $p$ of the bilinear oil dampers were found to be, $V_{r}=64 \mathrm{~mm} / \mathrm{sec}$ and $454 p=0.068$, respectively (Kasai et al. (2008); Ooki et al. (2009); Hikino 2012).

455 The test structure was subjected to the three components of the JR Takatori record from the 1995 Kobe 456 earthquake. These components were scaled incrementally at $50 \%$, and $100 \%$ of the unscaled intensity of 457 the same ground motion. Further details regarding the testing program can be found in Kasai and Matsuda 458 (2014).

459 A 3-Dimensional (3D) model of the test structure was developed in the OpenSees simulation platform. 460 The steel beams and columns were modeled with a single force-based distributed plasticity beam-column 461 element with five integration points along their length. In order to trace flexural yielding within the cross 462 sections a combined isotropic/kinematic material model (Menegotto and Pinto 1973) was assigned to the 463 fiber-based cross sections that were assigned to the force-based nonlinear beam-column elements. The 464 fiber discretization of each cross section consisted of $5 \times 3$ fiber elements along the width and thickness of 465 flanges and webs, respectively. The measured material properties reported by (Kasai and Matsuda 2014) 466 were explicitly assigned to the various steel beam and columns of the test structure. The reinforced 467 concrete slab on top of the steel beams was modeled with a concrete material (Yassin 1994), which 468 accounts for the effect of linear tension softening of the concrete. The effective width of the concrete slab 469 was calculated based on Section I3.1a of ANSI/AISC 360-10 (AISC 2010). Rigid diaphragms were 470 assigned at each floor level. The P-Delta transformation was assigned to the steel members of the test 471 structure to simulate the second order effects. The viscous damping forces of the test structure were 472 simulated with the Rayleigh model. In particular, $2 \%$ damping ratio was assigned to the first and third 473 modes of the 3-D model. Two seismic intensities (50\% and $100 \%)$ were considered for the evaluation 474 presented herein. Nonlinear response history analysis with direct integration of the equations of motion 475 was conducted. The Newmark's average acceleration method (Newmark 1959) was used for this purpose. 
This peer-reviewed published paper appears as: Akcelyan, S., Lignos, D. G. and Hikino, T. (2018). "Adaptive Numerical Method Algorithms for Nonlinear Viscous and Bilinear Oil Damper Models Subjected to Dynamic Loading". Soil Dynamics and Earthquake Engineering, Vol. 113, pp. 488-502. DOI: 10.1016/j.soildyn.2018.06.021

The integration time step was taken equal to $d t=0.01 \mathrm{sec}$. A detailed summary of the developed numerical

477 model of the test structure can be found in Lignos (2012) and (Akcelyan et al. 2016).

478 Figure 14 shows a comparison of the measured (noted as Test-50 and Test-100) and computed absolute 479 peak values of story drift ratios, story shear forces and floor absolute accelerations along the height of the 480 test structure with nonlinear viscous dampers under $50 \%$ and $100 \%$ of the unscaled Takatori record in 481 both loading directions (i.e., directions $\mathrm{X}$ and $\mathrm{Y}$ ). In order to illustrate the efficiency of the adaptive 482 integration techniques for the numerical solution of viscous dampers including their axial flexibility, two 483 types of nonlinear response history analyses are carried out. In the first one (noted as NRHA1) the axial 484 flexibility of the dampers is neglected. In the second one (noted as NRHA2) the axial flexibility of the damper is considered. Note that the average absolute errors of global peak engineering demand parameters (EDPs) shown in Figure 14 increase from $7 \%$ to $27 \%$ when the axial flexibility of the damper

487 is disregarded. In the Y-loading direction, the average absolute errors along the height of the test structure are much larger than those in the X-loading direction. In particular, the predicted peak EDPs are underestimated by more than $45 \%$ in average. Referring to Figure 15 , nearly identical findings hold true for the test structure with oil dampers. These simple comparisons indicate the importance of rigorous 491 mathematical models, such as the nonlinear Maxwell model, to accurately represent the hysteretic 492 response of viscous dampers including their axial flexibility. In this case, the advantage of the proposed 493 adaptive numerical method techniques to overcome typical convergence problems during nonlinear 494 response history analyses of large-scale finite element models with fairly large integration steps is also 495 pronounced.

496 Figure 16 illustrates the measured hysteretic response of the damper portion $\left(K_{d}\right.$ and $\left.C_{d}\right)$ of the nonlinear 497 viscous and bilinear oil dampers installed in the first story of the test structure in X-and Y- loading 498 directions, respectively, for the $100 \%$ seismic intensity of the JR Takatori record. In the same figure we 499 have superimposed the simulated hysteretic response of the same components based on NRHA of the 3D 
This peer-reviewed published paper appears as: Akcelyan, S., Lignos, D. G. and Hikino, T. (2018). "Adaptive Numerical Method Algorithms for Nonlinear Viscous and Bilinear Oil Damper Models Subjected to Dynamic Loading". Soil Dynamics and Earthquake Engineering, Vol. 113, pp. 488-502. DOI: 10.1016/j.soildyn.2018.06.021

model representation of the test structure with nonlinear viscous dampers and bilinear oil dampers based on the proposed adaptive integration techniques discussed in this paper. From Figure 16 it is evident that in both cases the proposed numerical models are rational and are able to capture fairly well both the peak damper forces as well as the damper displacement amplitudes.

The efficiency of the presented algorithms in computing the numerical solutions of the damper devices presented herein has been also evaluated in cases that steel frame buildings retrofitted with nonlinear viscous dampers exhibit inelastic behavior during severe ground motion shaking (Akcelyan 2017, Akcelyan and Lignos 2018, Wang and Mahin, 2017). It was found in all cases that the proposed numerical schemes have excellent convergence characteristics.

\section{Summary and Conclusions}

This paper discusses the implementation of advanced adaptive numerical integration algorithms for the numerical solution of the constitutive equations that describe the force-displacement relation of viscous dampers under random vibrations. The integration schemes are implemented in an open source finite element analysis program in order to calculate fourth- and fifth-order accurate numerical solutions of a damper force under dynamic loading when the axial flexibility of the respective viscous damper is considered in the mathematical model representation of the damper. Through a sensitivity study, the efficiency of the adaptive integration algorithm over traditional integration schemes for the numerical solution of initial value problems is demonstrated. In particular, it is shown that even in cases that involve nonlinear viscous dampers with large axial stiffness and small velocity exponents a high-accuracy numerical solution of the force-displacement relations of the respective damper is achieved with relatively large integration steps and only few sub-step iterations. In the case of bilinear oil dampers with large axial stiffness an alternative adaptive numerical integration algorithm is also proposed. This integration scheme is able to provide same accuracy solutions with the adaptive Dormand-Prince iterative method but with 
This peer-reviewed published paper appears as: Akcelyan, S., Lignos, D. G. and Hikino, T. (2018). "Adaptive Numerical Method Algorithms for Nonlinear Viscous and Bilinear Oil Damper Models Subjected to Dynamic Loading". Soil Dynamics and Earthquake Engineering, Vol. 113, pp. 488-502. DOI: 10.1016/j.soildyn.2018.06.021

524 much smaller number of sub-step iterations. The employed integration schemes allow for the 525 investigation of the sensitivity of the viscous damper behaviour to its axial stiffness. The adaptive 526 integration schemes for the numerical solution of the nonlinear Maxwell model are validated through a

527 series of comparisons with damper component tests as well as system-level experimental data from full528 scale shake table tests of a 5-story steel frame building with nonlinear viscous and bilinear oil dampers.

529 The validation studies underscore the efficiency of the proposed integration schemes in predicting the 530 global and local engineering demand parameters of frame buildings equipped with supplemental damping 531 devices at a relatively low computational cost.

\section{Acknowledgements}

534 The authors express their sincere thanks to the research team who conducted the full-scale shake table 535 tests of the 5-story steel frame building with various types of dampers (Leader: Professor Kazuhiko Kasai, 536 Tokyo Institute of Technology) and to the National Research Institute for Earth Science and Disaster 537 Prevention for providing the experimental data for the needs of this paper. The authors also acknowledge 538 the financial support from Fonds de recherche du Québec Nature et technologies (Grant No. 2013 - NC539 166845). The findings in this paper are those of the authors and do not necessary reflect the view of the 540 sponsors. 


\section{References}

AISC (2010). "Specification for structural steel buildings." ANSI/AISC 360-10, American Institute of Steel Construction, Chicago, IL.

Akcelyan, S., Lignos, D. G., Hikino, T., and Nakashima, M. (2016). "Evaluation of simplified and stateof-the-art analysis procedures for steel frame buildings equipped with supplemental damping devices based on E-Defense full-scale shake table tests." Journal of Structural Engineering, $142(6), 04016024$.

Akcelyan, S., and Lignos, D.G. (2018). "Seismic retrofit of steel tall buildings with bilinear oil dampers." Proc., $16^{\text {th }}$ European Conference on Earthquake Engineering, Thessaloniki, Greece, 18-21 June 2018.

BilinearOilDamper (2015). "BilinearOilDamper material." OpenSeesWiki online manual, $<$ http://opensees.berkeley.edu/wiki/index.php/BilinearOilDamper_Material $>$. (Aug. 6, 2015).

Black, C., and Makris, N. (2007). "Viscous heating of fluiddampers under small and large amplitude motions: experimental studies and parametric modeling." Journal of Engineering Mechanics, 133(5), 566-577.

Buchanan, A., Bull, D., Dhakal, R., MacRae, G., Palermo, A., and Pampanin, S. (2011). "Base isolation and damage-resistant technologies for improved seismic performance of buildings: A report written for the Royal Commission of Inquiry into building failure caused by the Canterbury earthquakes." Research Report 2011-02, Department of Civil and Natural Resources Engineering, University of Canterbury, Christchurch.

Butcher, J. C. (1996). "A history of Runge-Kutta methods." Applied Numerical Mathematics, 20(3), 247260.

Chang, K. C., Soong, T. T., Oh, S.-T., and Lai, M. L. (1995). "Seismic behavior of steel frame with added viscoelastic dampers." Journal of Structural Engineering, 121(10), 1418-1426.

Chen, Y.-T., and Chai, Y. H. (2011). "Effects of brace stiffness on performance of structures with supplemental Maxwell model-based brace-damper systems." Earthquake Engineering \& Structural Dynamics, 40(1), 75-92.

Christopoulos, C., and Filiatrault, A. (2006). Principles of supplemental damping and seismic isolation, IUSS Press, Milan, Italy.

Constantinou, M., Tsopelas, P., Hammel, W., and Sigaher, A. (2001). "Toggle-brace-damper seismic energy dissipation systems." Journal of Structural Engineering, 127(2), 105-112.

Constantinou, M. C., Soong, T. T., and Dargush, G. F. (1998). "Passive energy dissipation systems for structural design and retrofit." MCEER-Monograh No: 1, Multidisciplinary Center for Earthquake Engineering Research, University of Buffalo., USA.

Constantinou, M. C., and Symans, M. D. (1993). "Experimental study of seismic response of buildings with supplemental fluid dampers." The Structural Design of Tall Buildings, 2(2), 93-132.

Diotallevi, P. P., Landi, L., and Dellavalle, A. (2012). "A methodology for the direct assessment of the damping ratio of structures equipped with nonlinear viscous dampers." Journal of Earthquake Engineering, 16(3), 350-373.

Dong, B., Sause, R., and Ricles, J. M. (2015). "Accurate real-time hybrid earthquake simulations on large-scale MDOF steel structure with nonlinear viscous dampers." Earthquake Engineering \& Structural Dynamics, 44(12), 2035-2055.

Dong, B., Sause, R., and Ricles, J.M. (2018). "Seismic erformance of steel MRF structures with nonlinear viscous dampers from real-time hybrid simulations." Proc., $9^{\text {th }}$ International Conference on the Behaviour of Steel Structures in Seismic Areas, Christchurch, New Zealand, February 14-17, 2018.

Dormand, J. R., and Prince, P. J. (1980). "A family of embedded Runge-Kutta formulae." Journal of Computational and Applied Mathematics, 6(1), 19-26. 
Griffiths, D., Higham, D.J. (2010). "Numerical methods for ordinary differential equations - Initial value problems", Springer Series ISBN 978-0-85729-148-6.

Hairer, E., Norsett, E., Wanner, G. (1993). "Solving ordinary differential equations I - Nonstiff problems", Springler Series in Computational Mathematics.

Hikino, T. (2012). "Full-scale shaking table test and analysis of the dynamic characteristics verification that govern the seismic behavior of steel buildings with supplemental damping." Ph.D. Dissertation, Kyoto University, Japan (in Japanese).

Hwang, J., Huang, Y., Yi, S., and Ho, S. (2008). "Design formulations for supplemental viscous dampers to building structures." Journal of Structural Engineering, 134(1), 22-31.

Ichihasi, S., Okuzono, T., Takahashi, O., Usami, M., Ninomiya, M., Tsuyuki, Y., and Ishida, Y. (2000). "Vibration test of a frame which has an oil-damper brace." Proc., The $12^{\text {th }}$ World Conference on Earthquake Engineering (WCEE), Auckland, New Zealand.

Kasai, K., Ito, H., Ooki, Y., Hikino, T., Kajiwara, K., Motoyui, S., Ozaki, H., and Ishii, M. (2010). "Fullscale shake table tests of 5-story steel building with various dampers." Proc., 7th International Conference on Urban Earthquake Engineering (7CUEE) \& 5th International Conference on Earthquake Engineering (5ICEE), Tokyo Institute of Technology, Tokyo, Japan.

Kasai, K., and Matsuda, K. (2014). "Full-scale dynamic testing of response-controlled buildings and their components: concepts, methods, and findings." Earthq. Engin. Engin. Vib., 13(1), 167-181 English.

Kasai, K., Mita, A., Kitamura, H., Matsuda, K., Morgan, T. A., and Taylor, A. W. (2013). "Performance of seismic protection technologies during the 2011 Tohoku-Oki Earthquake." Earthquake Spectra, 29(S1), S265-S293.

Kasai, K., and Nishimura, T. (2004). "Equivalent linearization of passive control system with oil damper bilinearly dependent on velocity." Journal of Structural and Construction Engineering, AIJ, (583), 47-54 (in Japanese).

Kasai, K., Ogura, T., and Suzuki, A. (2007). "Passive control desing method based on tuning equivalent stiffness of nonlinear viscous dampers." Journal of Structural and Construction Engineering, AIJ, , 76(618), 97-104 (in Japanese).

Kasai, K., Oohara, K., and Sekiguchi, Y. (2004). "JSSI manual for building passive control technology part-10 time-history analysis model for viscous dampers." Proc., The $13^{\text {th }}$ World Conference on Earthquake Engineering, Vancouver, B.C., Canada.

Kasai, K., Ooki, Y., Ishii, M., Ozaki, H., Ito, H., Motoyui, S., Hikino, T., and Sato, E. (2008). "Valueadded 5-story steel frame and its components: Part 1 - Full-scale damper tests and analyses." Proc., The 14th World Conference on Earthquake Engineering, Beijing, China.

Kasai, K., Suzuki, A., and Oohara, K. (2003). "Equivalent linearization of a passive control system having viscous dampers dependent on fractional power of velocity." Journal of Structural and Construction Engineering, AIJ,(574), 77-84 (in Japanese).

Kasai, K., Takahashi, O., and Sekiguchi, Y. (2004). "JSSI manual for building passive control technology part-10 time-history analysis model for nonlinear oil dampers." Proc., The $13^{\text {th }}$ World Conference on Earthquake Engineering, Vancouver, B.C., Canada.

Kutta, W. (1901). "Beitrag zur näherungsweisen Integration totaler Differentialgleichungen." Zeitschrift für Mathematik und Physik, 46, 435-453.

Lavan, O., and Avishur, M. (2013). "Seismic behavior of viscously damped yielding frames under structural and damping uncertainties." Bull Earthquake Eng, 11(6), 2309-2332 English.

Lavan, O., Cimellaro, G., and Reinhorn, A. (2008). "Noniterative optimization procedure for seismic weakening and damping of inelastic structures." Journal of Structural Engineering, 134(10), $1638-1648$.

Liang, Z., Lee, G. C., and Dargush, G. F. (2011). Structural damping: Applications in seismic response modification, CRC Press, USA. 
661

662

663

664

665

666

667

668

669

670

671

672

673

674

675

676

677

678

679

680

681

682

683

684

685

686

Lignos, D. G. (2012). "Modeling and experimental validation of a full scale 5-story steel building equipped with tripple friction pendulum bearings: E-defense blind analysis competition." Proc., 9th International Conference on Urban Earthquake Engineering (9CUEE) \& 4th Asia Conference on Earthquake Engineering, Center for Urban Earthquake Engineering (CUEE), Tokyo Institute of Technology, Tokyo.

Lin, W.-H., and Chopra, A. K. (2002). "Earthquake response of elastic SDF systems with non-linear fluid viscous dampers." Earthquake Engineering \& Structural Dynamics, 31(9), 1623-1642.

Londoño, J. M., Neild, S. A., and Wagg, D. J. (2013). "A noniterative design procedure for supplemental brace-damper systems in single-degree-of-freedom systems." Earthquake Engineering \& Structural Dynamics, 42(15), 2361-2367.

Makris, N., and Constantinou, M. (1991). "Fractional - derivative maxwell model for viscous dampers." Journal of Structural Engineering, 117(9), 2708-2724.

Maxwell, J. C. (1867). "On the dynamical theory of gases." Philosophical Transactions of the Royal Society of London, 157, 49-88.

McKenna, F. T. (1997). "Object-oriented finite element programming: frameworks for analysis, algorithms and parallel computing." Ph.D. Dissertation, University of California, Berkeley.

Menegotto, M., and Pinto, P. E. (1973). "Method of analysis for cyclically loaded reinforced concrete plane frames including changes in geometry and non-elastic behaviour of elements under combined normal force and bending." Proc., IABSE, Symp. on Resistance and Ultimate Deformability of Structures Acted on by Well Defined Repeated Loads, IABSE-AIPC-IVBH, ETH Zurich, Zurich, Switzerland, 15-22.

Miranda, E., Mosqueda, G., Retamales, R., and Pekcan, G. (2012). "Performance of nonstructural components during the 27 February 2010 Chile Earthquake." Earthquake Spectra, 28(S1), S453S471.

Newmark, N. M. (1959). "A method of computation for structural dynamics." Journal of the Engineering Mechanics Division, ASCE, 85(3), 67-94.

Ohtani, K., Ogawa, N., Katayama, T., and Shibata, H. (2004). "Construction of E-Defense (3-D full-scale earthquake testing facility)." Proc., 13th World Conference on Earthquake Engineering, Vancouver, B.C., Canada.

Oohara, K., and Kasai, K. (2002). "Time history analysis models for nonlinear viscous dampers." Proc., Structural Engineers World Congress (SEWC), Yokohama, JAPAN.

Ooki, Y., Kasai, K., Motoyui, S., Kaneko, K., Kajiwara, K., and Hikino, T. (2009). "Full-scale tests of passively-controlled 5-story steel building using E-Defense shake table part 3: full-scale tests for dampers and beam-column subassemblies." Proc., STESSA 2009, Philadelphia, 93-99.

Pall, A. S., and Marsh, C. (1982). "Response of friction damped braced frames." Journal of the Structural Division, ASCE, 108(6), 1313-1323.

Pekcan, G., Mander, J. B., and Chen, S. S. (1999). "Fundamental considerations for the design of non linear viscous dampers." Earthquake Engineering \& Structural Dynamics, 28(11), 1405-1425.

Pollini, N., Lavan, O., and Amir, O. (2017). "Minimum-cost optimization of nonlinear fluid viscous dampers and their supporting members for seismic retrofitting." Earthquake Engineering \& Structural Dynamics, n/a-n/a.

Ramirez, O. M., Constantinou, M. C., Kircher, C. A., Whittaker, A. S., Johnson, M. W., Gomez, J. D., and Chrysostomou, C. Z. (2001). "Development and evaluation of simplified procedures for analysis and design of buildings with passive energy dissipation systems." MCEER-00-0010 2001, Multidisciplinary Center for Earthquake Engineering Research, University of Buffalo, USA.

Reinhorn, A. M., Li, C., and Constantinou, M. C. (1995). "Experimental \& analytical investigation of seismic retrofit of structures with supplemental damping, Part 1: Fluid viscous damping devices." 
NCEER-95-0001, National Center for Earthquake Engineering Research, University of Buffalo, USA.

Singh, M., Verma, N., and Moreschi, L. (2003). "Seismic analysis and design with maxwell dampers." Journal of Engineering Mechanics, 129(3), 273-282.

Sivaselvan, M. V., Lavan, O., Dargush, G.F., Kurino, H., Hyodo, Y., Fukuda, R., Sato, K., Apostolakis, G., and Reinhorn, A.M. (2009). "Numerical collapse simulation of large-scale structural systems using an optimization-based algorithm."Earthquake Engineering and Structural Dynamics, 38 (5), 655-677.

Soong, T., and Dargush, G. (1997). Passive energy dissipation systems in structural engineering, John Wiley \& Sons, Chichester, United Kingdom.

Symans, M., Charney, F., Whittaker, A., Constantinou, M., Kircher, C., Johnson, M., and McNamara, R. (2008). "Energy dissipation systems for seismic applications: current practice and recent developments." Journal of Structural Engineering, 134(1), 3-21.

Symans, M. D., and Constantinou, M. C. (1998). "Passive fluid viscous damping systems for seismic energy dissipation." ISET Journal of Earthquake Technology, 35(4), 185-206.

Takahashi, O., and Sekiguchi, Y. (2001). "Constitutive rule of oil damper with maxwell model and source code for analysis program." Proc., Passively Controlled Structure Symposium 2001, Yokohama, Japan.

Terenzi, G. (1999). "Dynamics of SDOF systems with nonlinear viscous damping." Journal of Engineering Mechanics, ASCE, 125 (8), 956-963.

Tsuyuki, Y., Gofuku, Y., Iiyama, F., and Kotake, Y. (2004). "JSSI manual for building passive control technology part-3 performance and quality control of oil damper." Proc., The $13^{\text {th }}$ World Conference on Earthquake Engineering, Vancouver, B.C., Canada.

ViscousDamper (2015). "ViscousDamper material." OpenSeesWiki online manual, $<$ http://opensees.berkeley.edu/wiki/index.php/ViscousDamper_Material $>$. (Sep. 30, 2016).

Wang, S., and Mahin, S.A. (2017). "Seismic retrofit of a high-rise steel moment-resisting frame using fluid viscous dampers." The Structural Design of Tall and Special Buildings, 26 (10), 1-11.

Yassin, M. H. M. (1994). "Nonlinear analysis of prestressed concrete structures under monotonic and cycling loads." Ph.D. Dissertation, University of California, Berkeley.

Yu, Y., Tsai, K., Li, C., Weng, Y., and Tsai, C. (2013). "Earthquake response analyses of a full-scale fivestory steel frame equipped with two types of dampers." Earthquake Engineering \& Structural Dynamics, 42(9), 1301-1320. 
Table 1: Properties of nonlinear viscous dampers and oil dampers (Hikino, 2012).

\begin{tabular}{|c|c|c|c|c|c|c|c|}
\hline \multirow[b]{2}{*}{ Frame } & \multirow[b]{2}{*}{ Story } & \multicolumn{3}{|c|}{$\begin{array}{l}\text { Nonlinear Viscous Damper } \\
\qquad(\alpha=0.38)\end{array}$} & \multicolumn{3}{|c|}{ 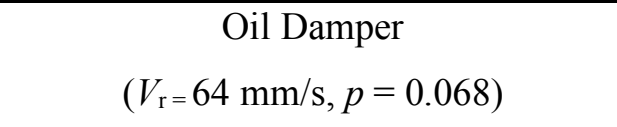 } \\
\hline & & $\begin{array}{c}C_{d} \\
{\left[\mathrm{KN} /(\mathrm{mm} / \mathrm{s})^{0.38}\right]}\end{array}$ & $\begin{array}{c}K_{d} \\
{[\mathrm{KN} / \mathrm{mm}]}\end{array}$ & $\begin{array}{c}K_{s} \\
{[\mathrm{KN} / \mathrm{mm}]}\end{array}$ & $\begin{array}{c}C_{d} \\
{[\mathrm{KN} /(\mathrm{mm} / \mathrm{s})]}\end{array}$ & $\begin{array}{c}K_{d} \\
{[\mathrm{KN} / \mathrm{mm}]}\end{array}$ & $\begin{array}{c}K_{s} \\
{[\mathrm{KN} / \mathrm{mm}]}\end{array}$ \\
\hline \multirow{4}{*}{$\begin{array}{c}X \\
\text { direction } \\
\text { (2 bays) }\end{array}$} & 4 & 49 & $119^{(\mathrm{a})}$ & 60 & 3.13 & 88 & 57 \\
\hline & 3 & 49 & $119^{(\mathrm{a})}$ & 60 & 6.25 & 137 & 85 \\
\hline & 2 & 98 & 193 & 104 & 6.25 & 137 & 85 \\
\hline & 1 & 98 & 193 & 101 & 12.5 & 274 & 146 \\
\hline \multirow{4}{*}{$\begin{array}{c}\mathrm{Y} \\
\text { direction } \\
\text { (1 bay) }\end{array}$} & 4 & 98 & 193 & 104 & 6.25 & 137 & 85 \\
\hline & 3 & 98 & 193 & 104 & 12.5 & 274 & 154 \\
\hline & 2 & 196 & 438 & 179 & 12.5 & 274 & 154 \\
\hline & 1 & 196 & 438 & 171 & 18.75 & 441 & 242 \\
\hline
\end{tabular}

721 (a) Estimated stiffness values $\left(K_{d}\right)$ for damper portion due to lack of data of dampers at third and fourth story (Yu et

722 al. 2013).

723

724

725

726

727 


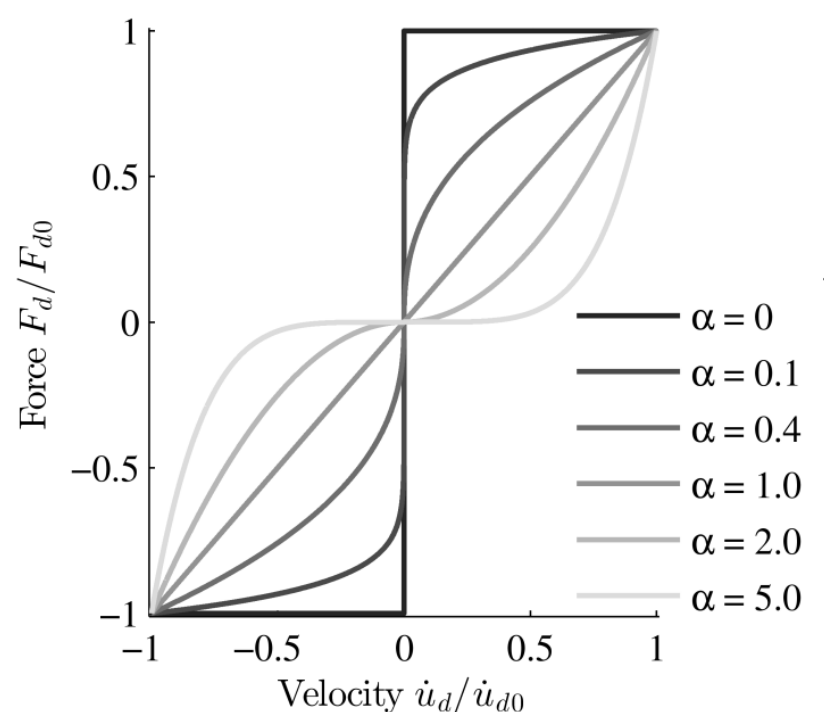

(a) Force - velocity relation

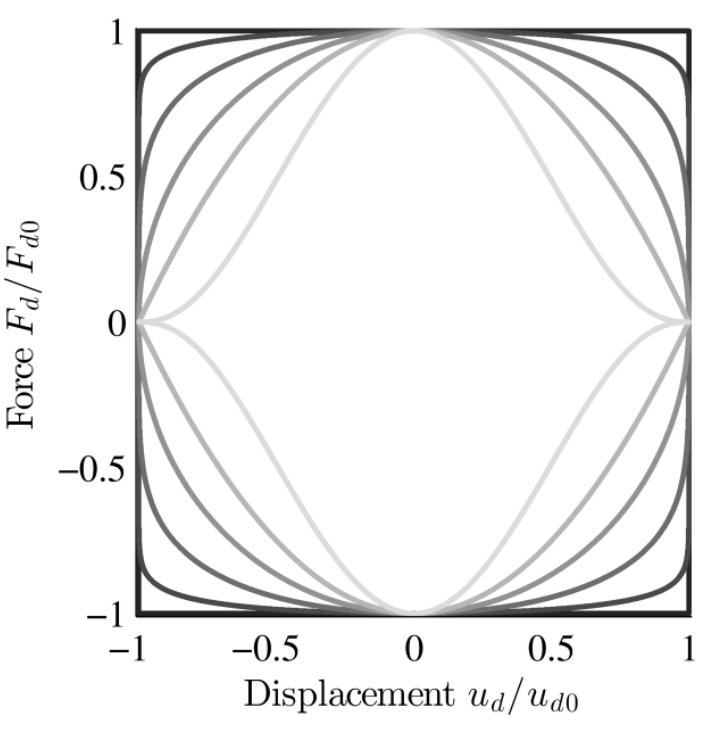

(b) Force - displacement relation

729

730 Figure 1: Hysteretic behaviour of nonlinear viscous dampers with various velocity exponents under

731 sinusoidal motion 


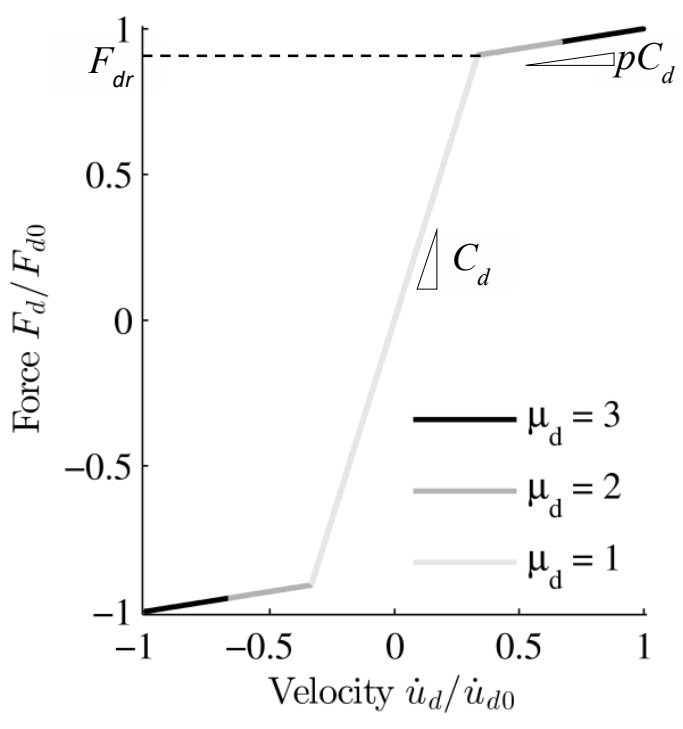

(a) Force - velocity relation

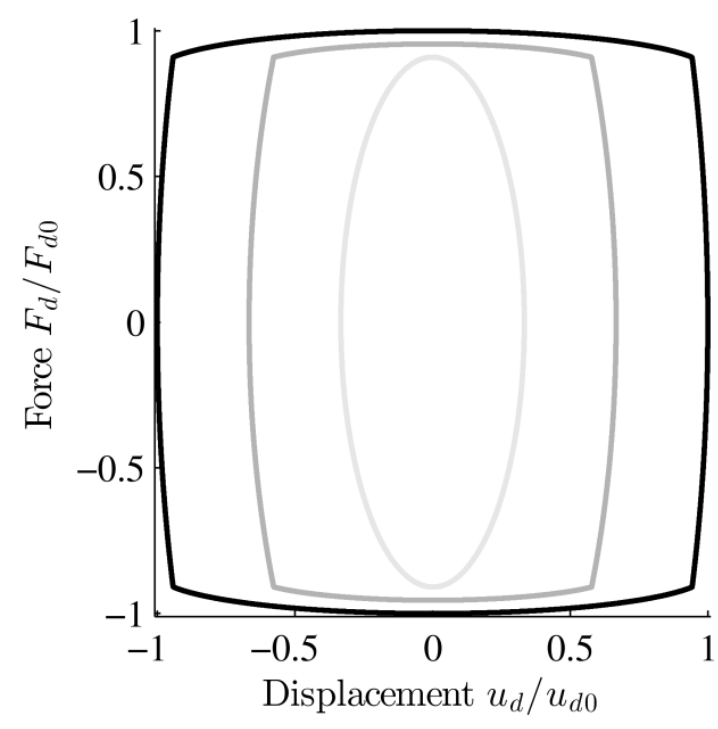

(b) Force - displacement relation

734

735 Figure 2: Hysteretic behaviour of bilinear oil dampers under sinusoidal motion with increasing loading 736 amplitudes 


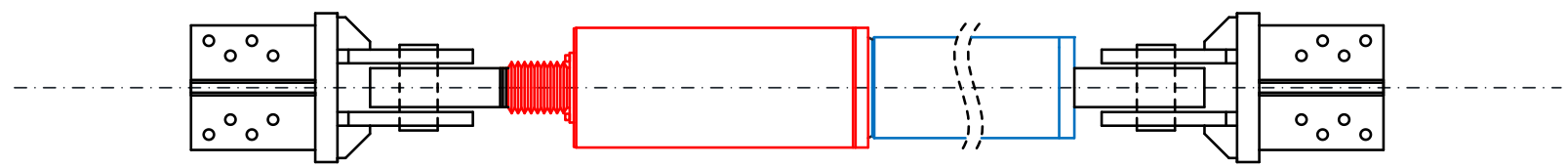

$\hookrightarrow$ Gusset $\hookrightarrow$ Clevis \& Brackets $\hookrightarrow$ Damper Portion $\hookrightarrow \hookrightarrow$ Brace $\hookrightarrow$ Clevis \& Brackets $\hookrightarrow$ Gusset

(a) Nonlinear viscous damper

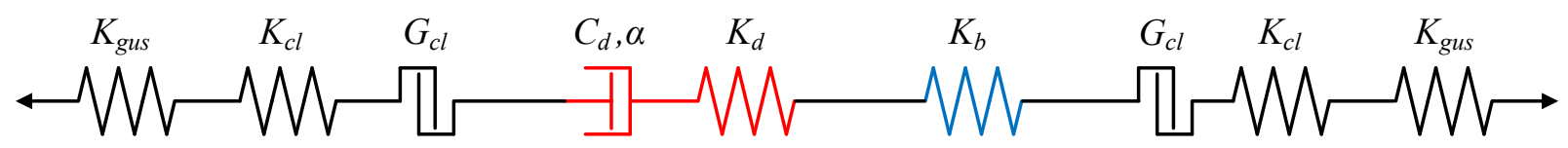

(b) Mechanical model for nonlinear viscous damper

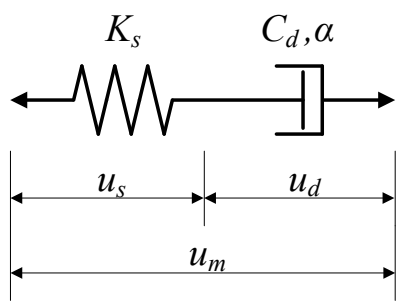

(c) Maxwell model

Figure 3: Schematic representation of nonlinear viscous damper including its mathematical model 

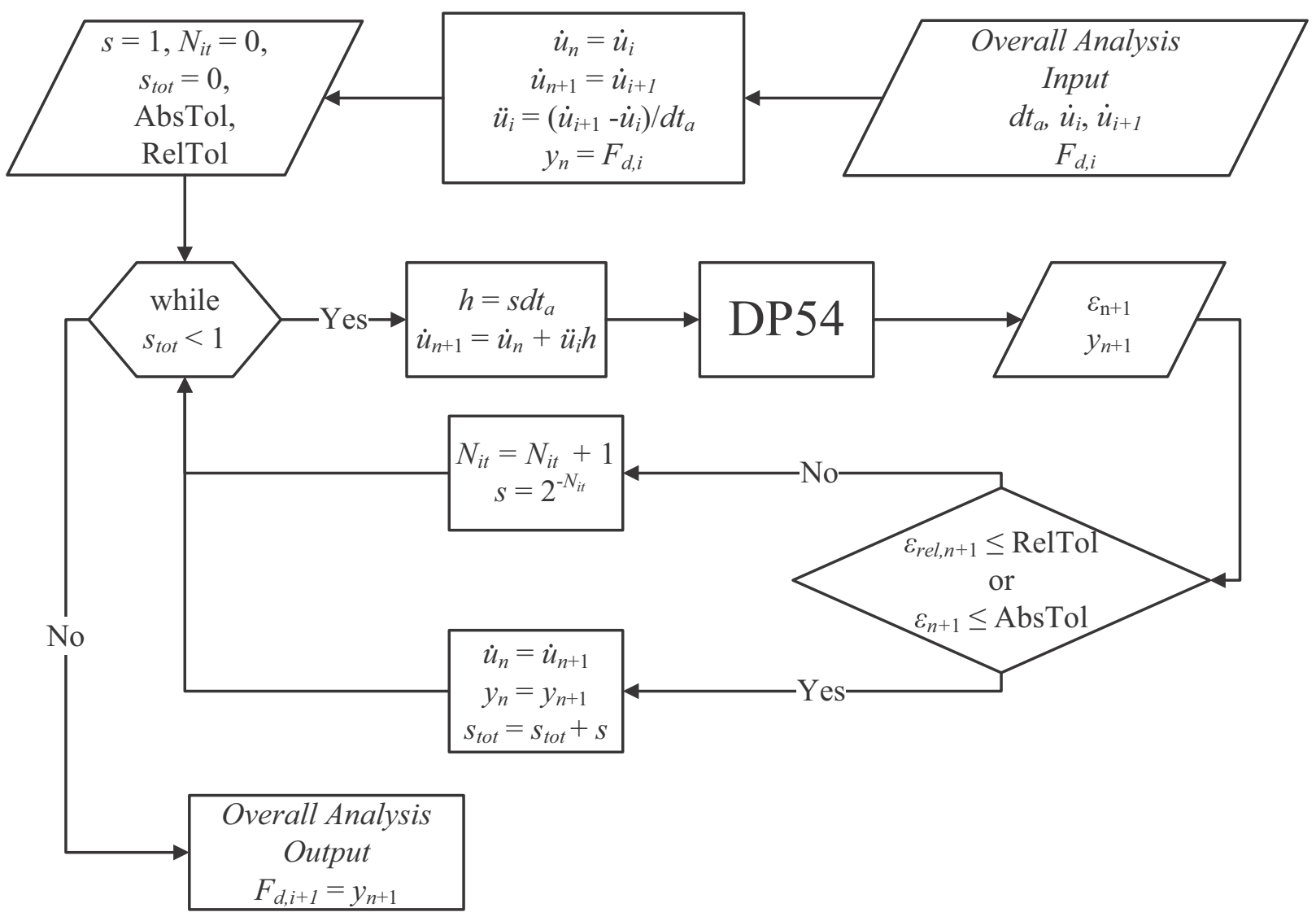

742 Figure 4: Flow chart of the numerical solution based on the adaptive DP54 explicit iterative method for

743 nonlinear viscous dampers 

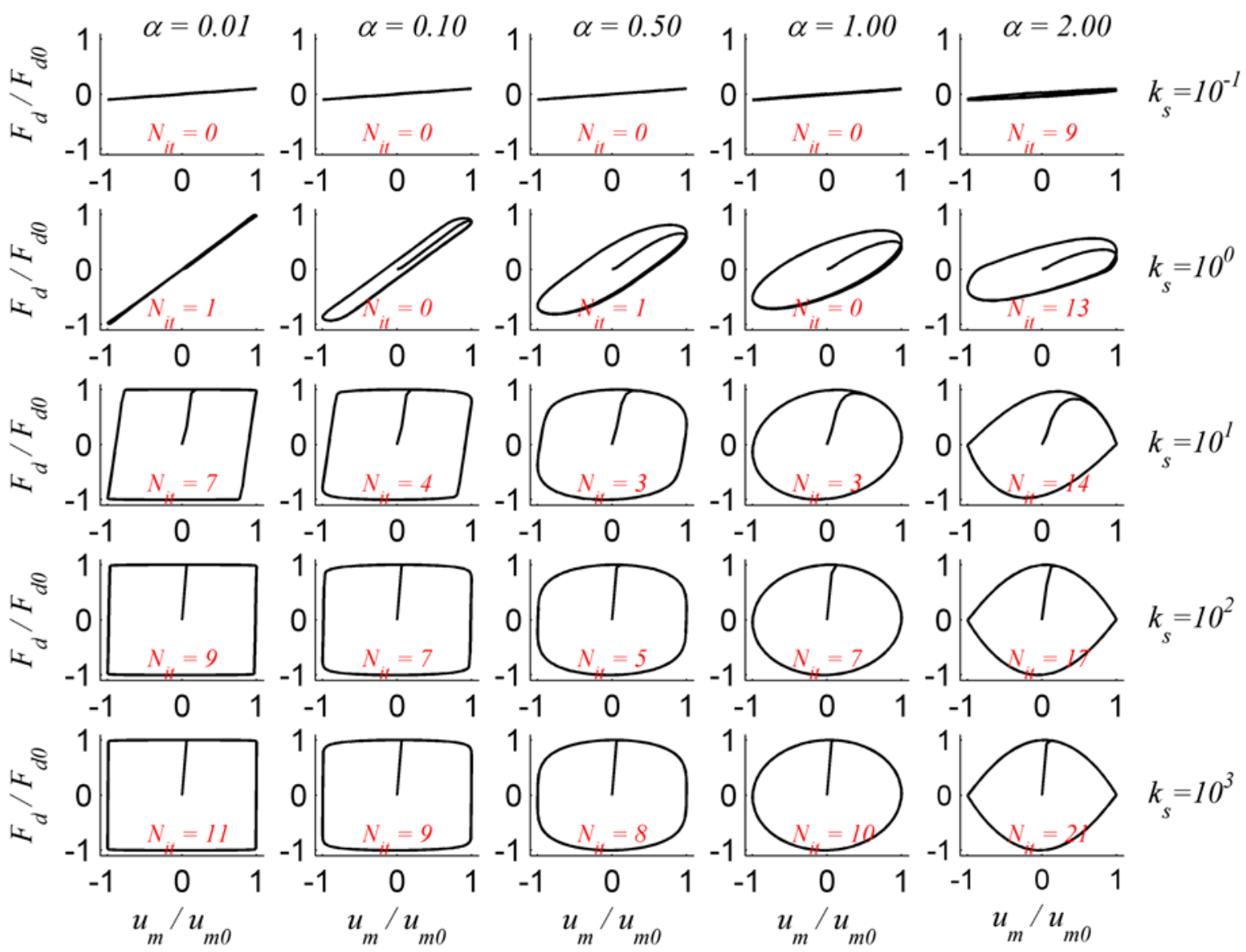

Figure 5: Force-displacement relations for nonlinear viscous dampers under sinusoidal displacement loading based on the adaptive DP54 iterative method 

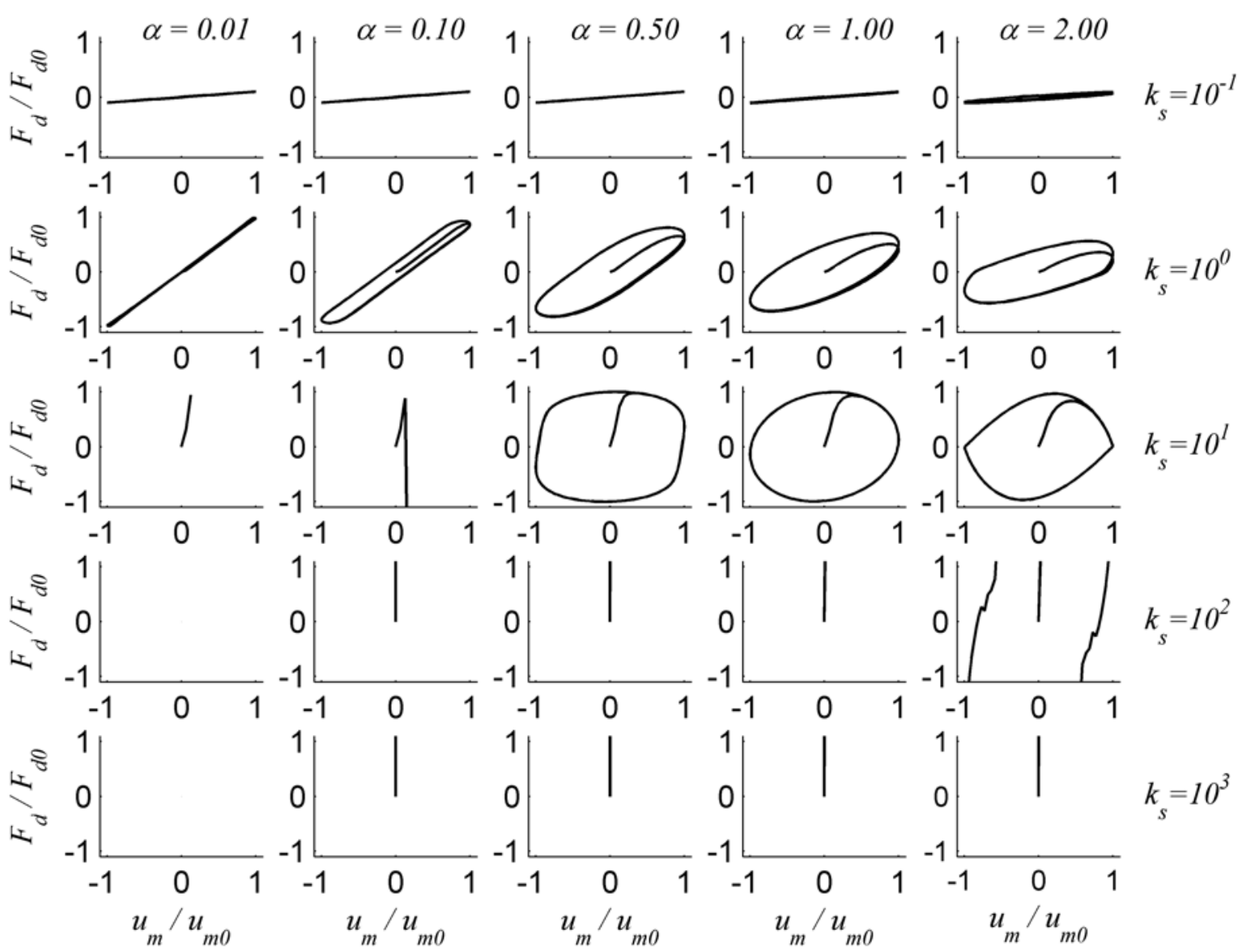

Figure 6: Force-displacement relations for nonlinear viscous dampers under sinusoidal displacement based on the classical $4^{\text {th }}$ order Runge-Kutta method 


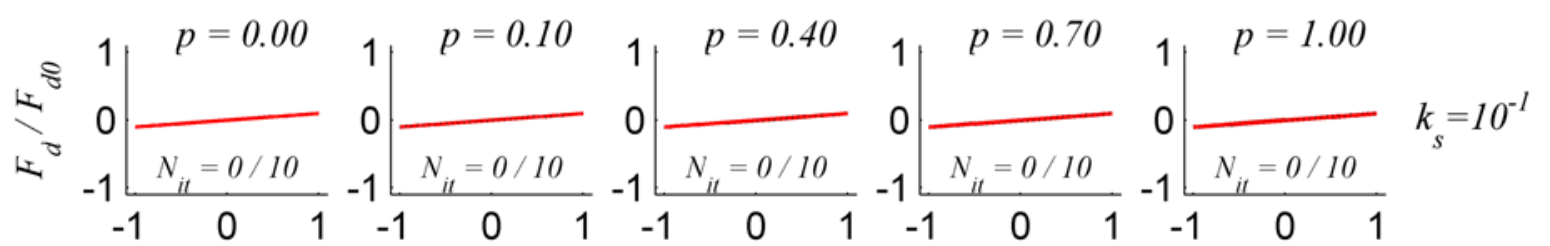
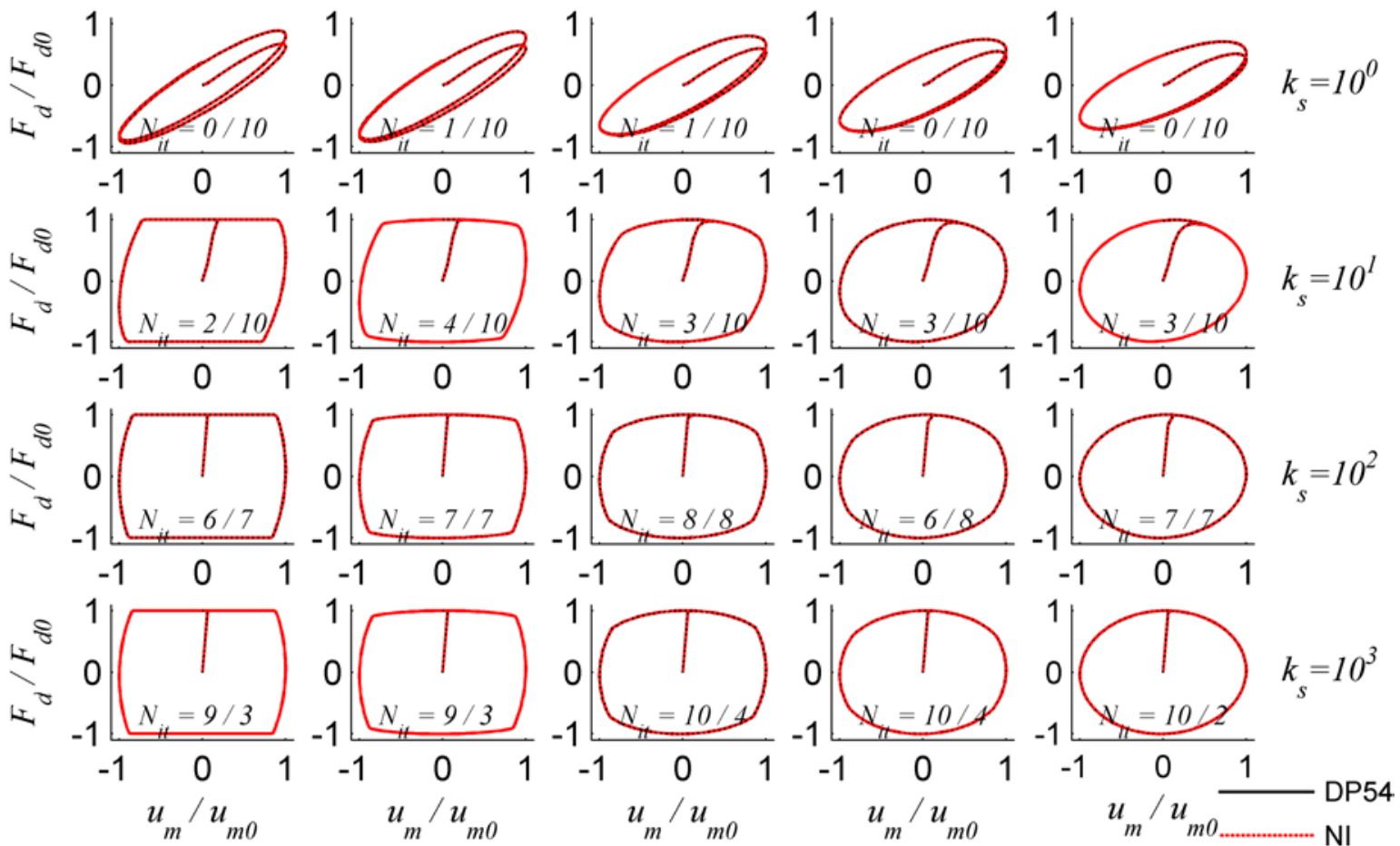

757 Figure 7: Comparison of the force-displacement relation predictions for bilinear oil dampers under

758 sinusoidal displacement based on the adaptive DP54 iterative method and the alternative adaptive

759 numerical integration algorithm (NI) for $\mu_{m}=2$ 


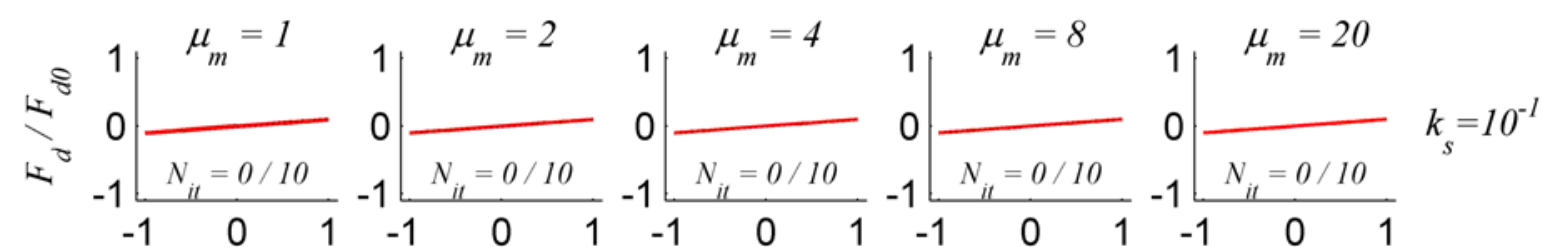
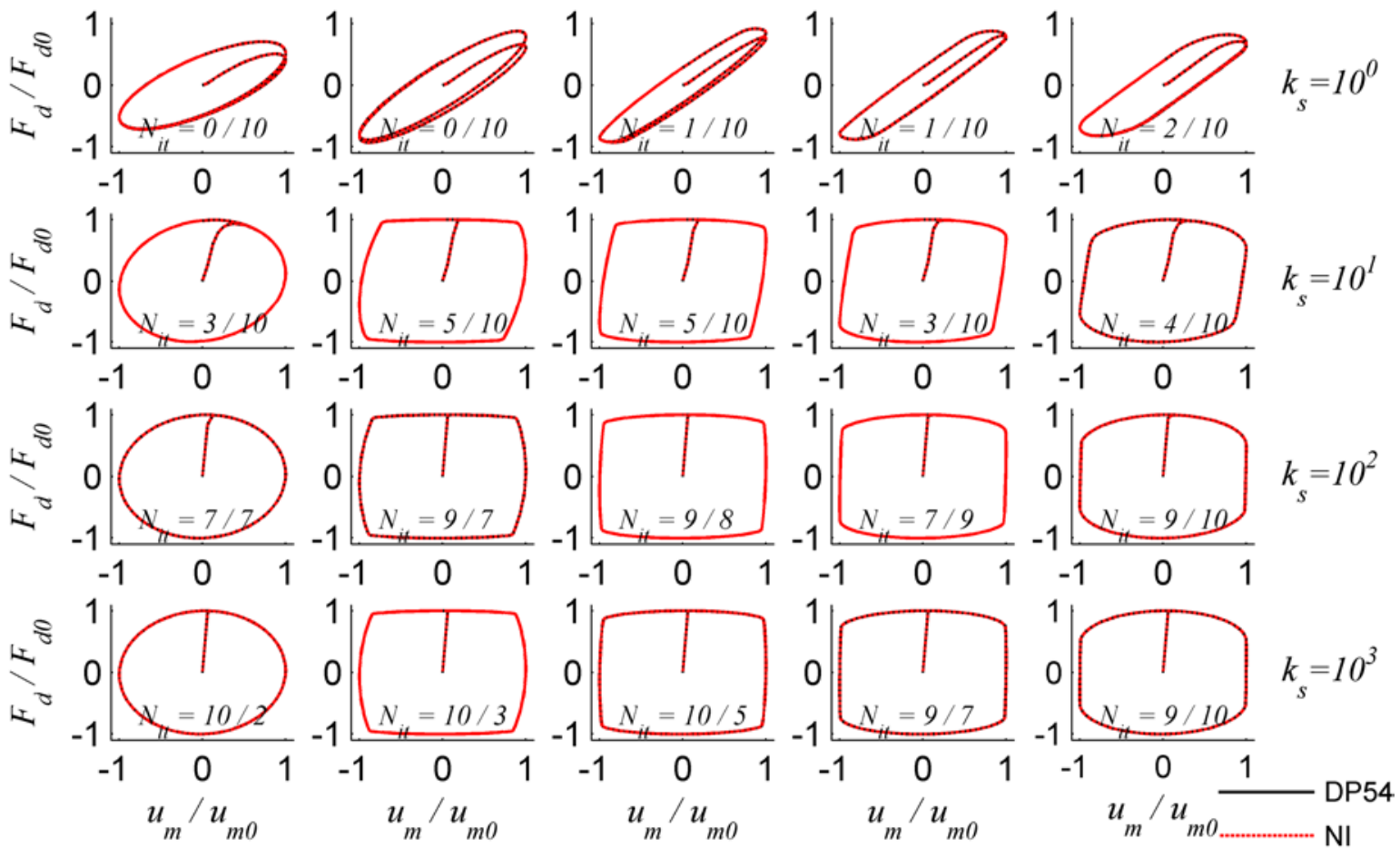

761

762 Figure 8: Force-displacement relations for bilinear oil dampers under sinusoidal displacement based on the adaptive DP54 iterative method and the alternative adaptive numerical integration algorithm (NI) for 


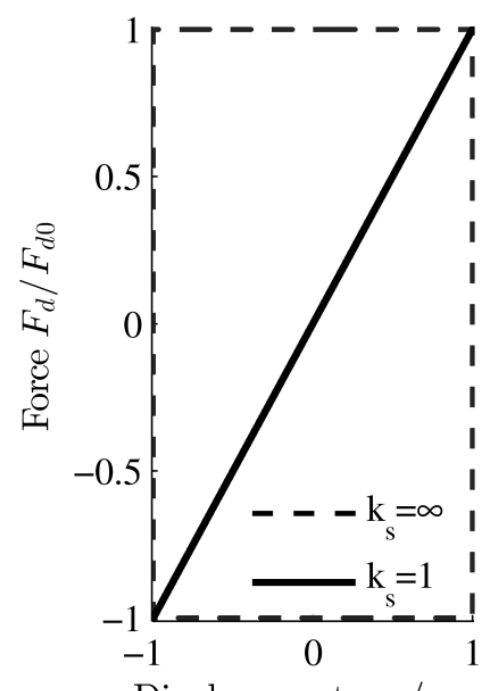

766

767

768

769

770

(a) $\alpha=0$

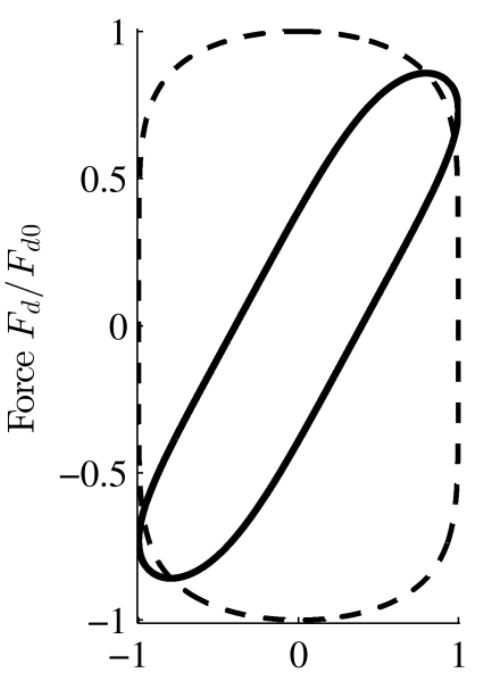

Displacement $u_{m} / u_{m 0}$

(b) $\alpha=0.30$

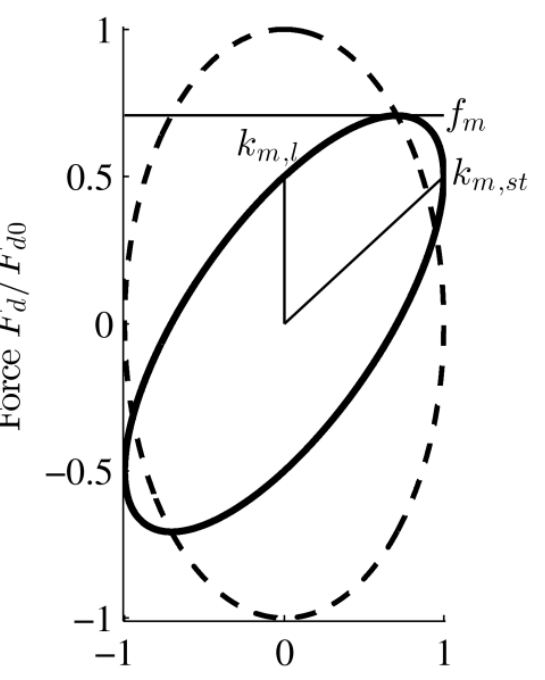

Displacement $u_{m} / u_{m 0}$

(c) $\alpha=1.0$

Figure 9: Variation of nonlinear viscous dampers force-displacement relations with different parameters under sinusoidal displacement and graphical definition of dynamic stiffness 

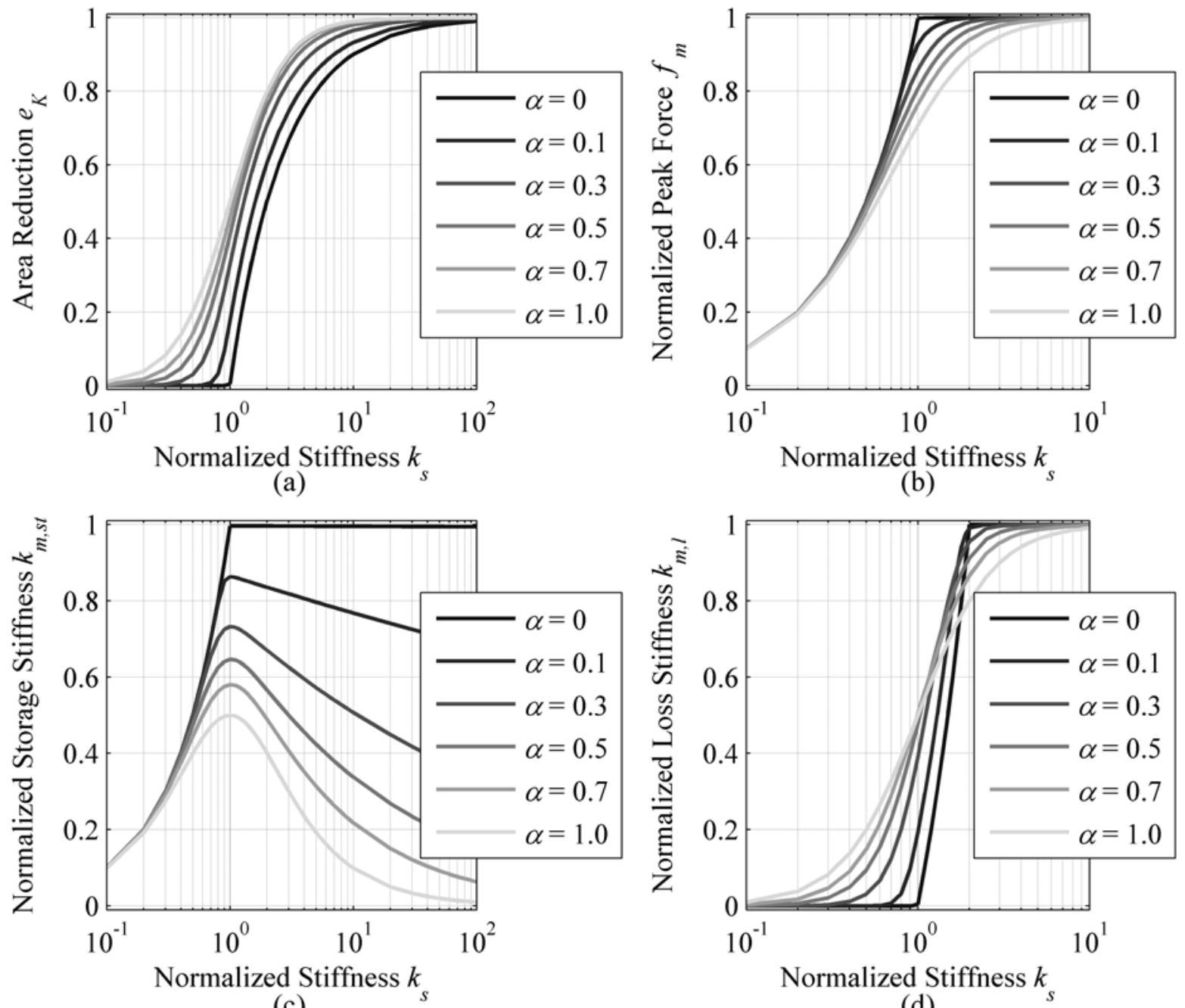

771

(c)

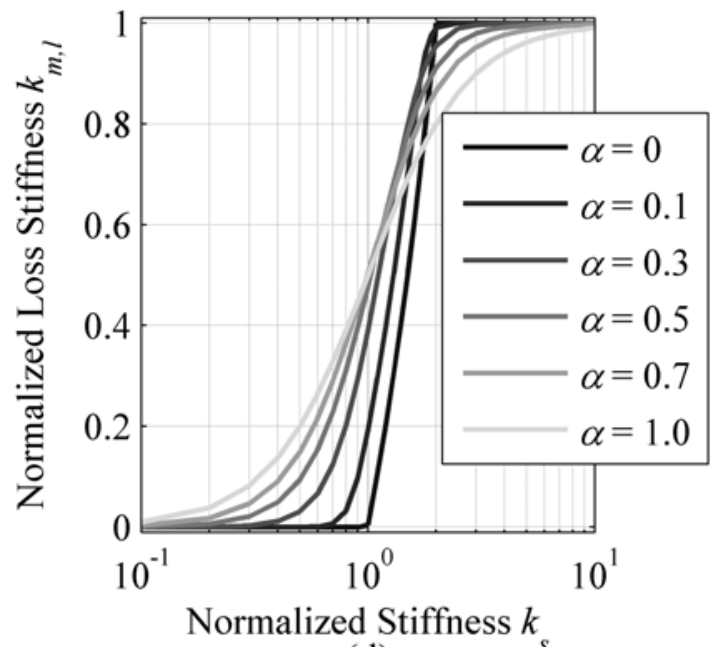

(d)

772

773 Figure 10: Effect of normalized stiffness on various properties of nonlinear viscous dampers with

774 different velocity exponents 


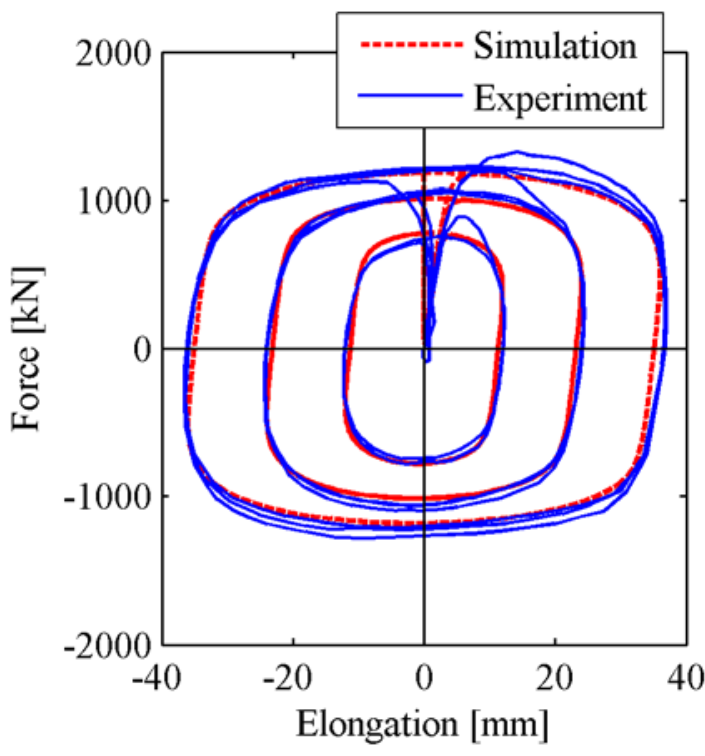

(a) $0.5 \mathrm{~Hz}$

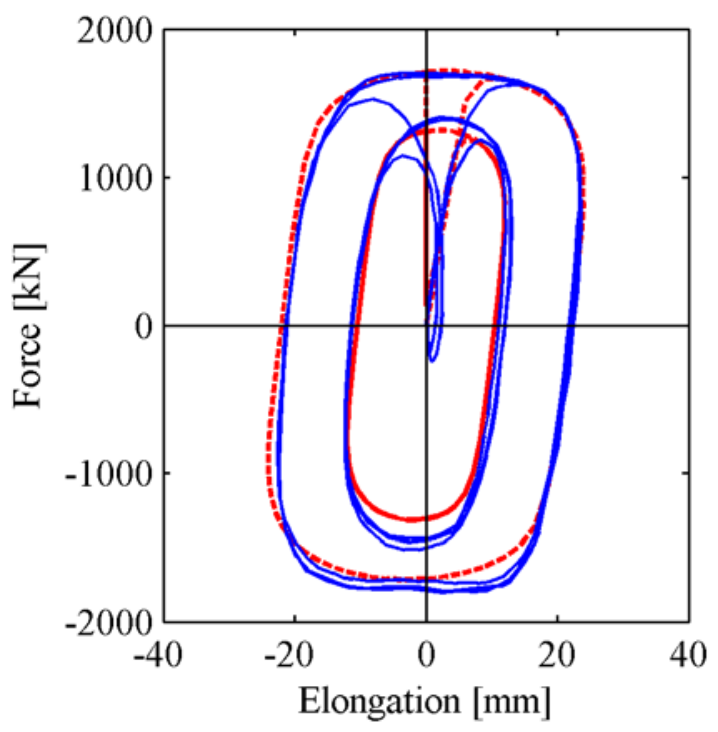

(b) $2 \mathrm{~Hz}$

778 Figure 11: Comparison of the simulated and experimental hysteretic response of nonlinear viscous

779 dampers under dynamic sinusoidal loading (experimental data adopted from Kasai et al. 2004b) 


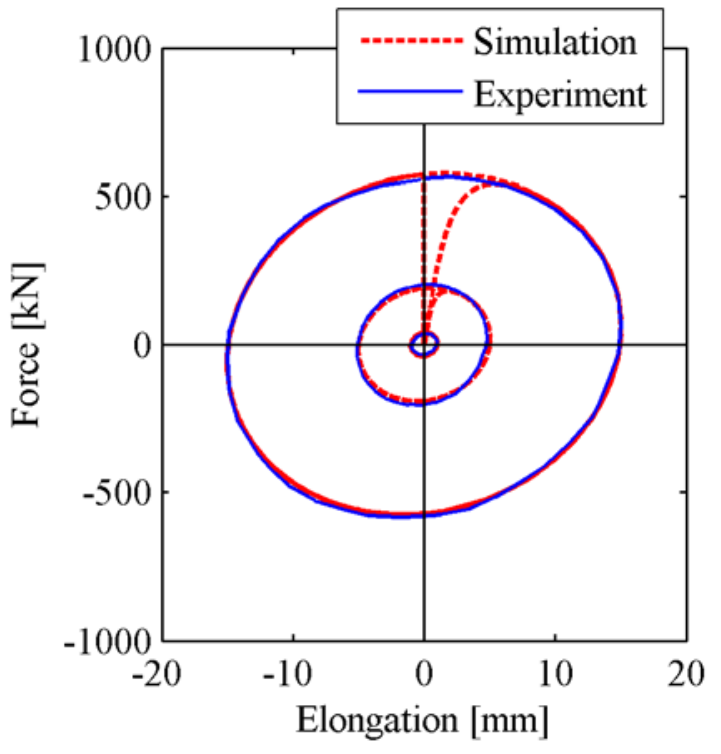

(a) $0.25 \mathrm{~Hz}$

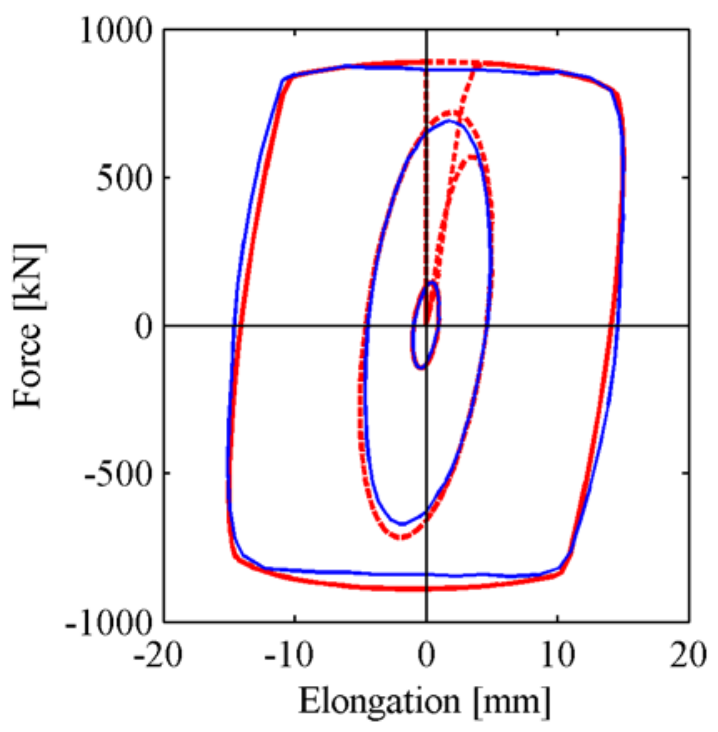

(b) $1 \mathrm{~Hz}$

782

783 Figure 12: Comparison of the simulated and experimental hysteretic response of bilinear oil dampers

784 under dynamic sinusoidal loading (experimental data adopted from Kasai et al. (2004b)

785

786 

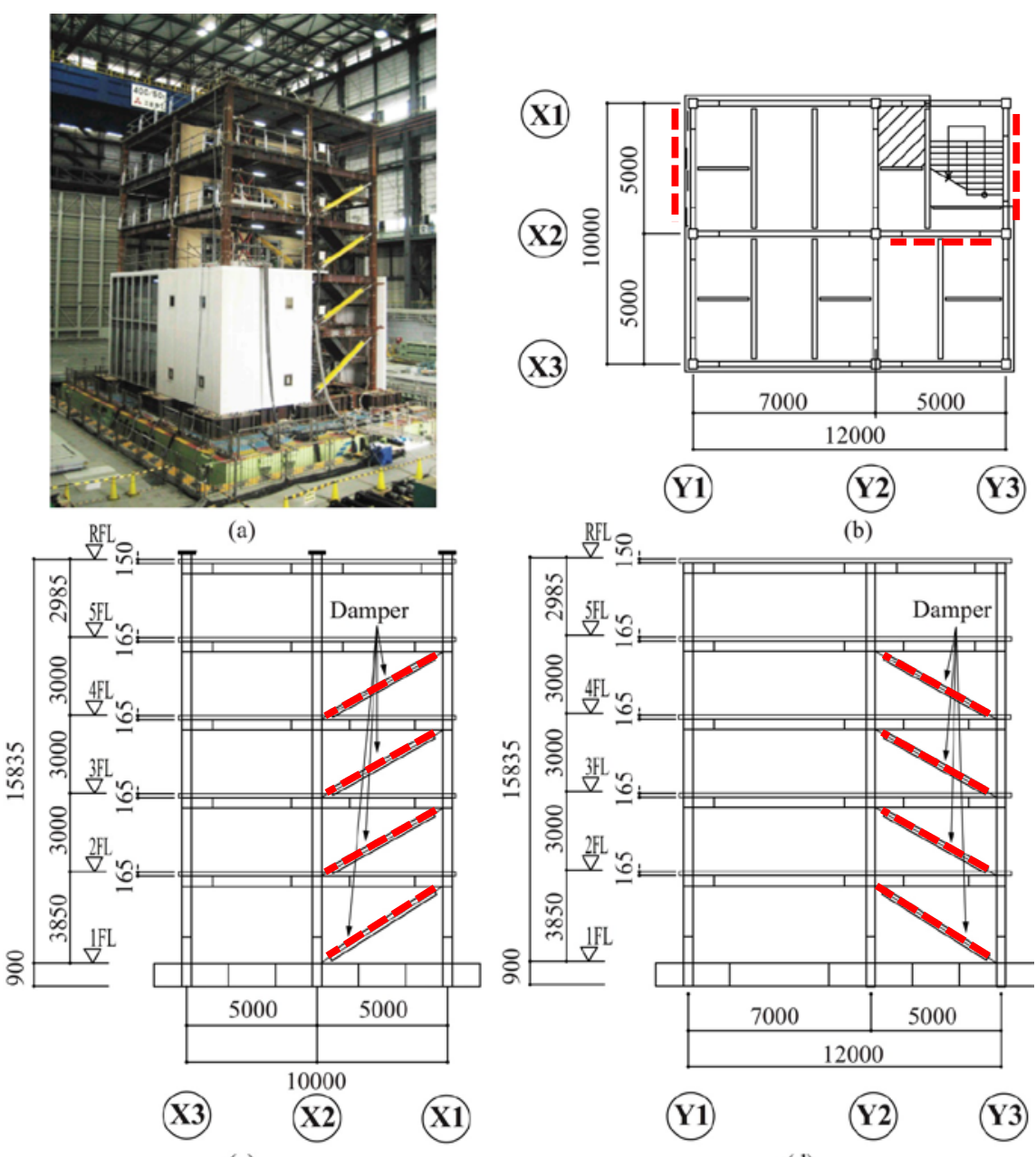

(c)

(d)

788 Figure 13: 5-story test-structure tested at E-Defense; (a) building after installation on the shake table; (b)

789 plan view (c) elevation view in X- loading direction; (d) elevation view in Y-loading direction (images

790 adopted from Akcelyan et al. (2016), dimensions in $\mathrm{mm}$ ) 


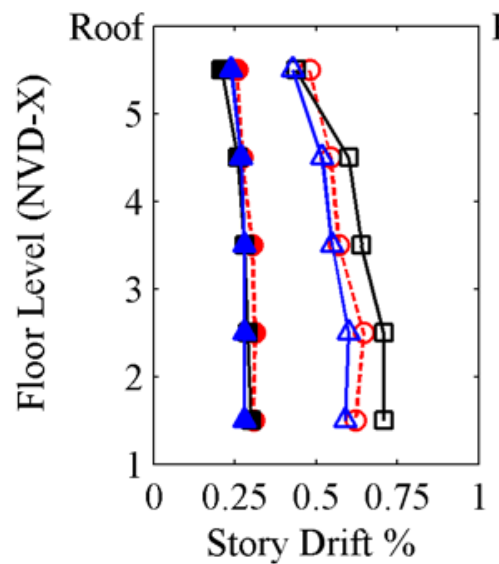

(a)

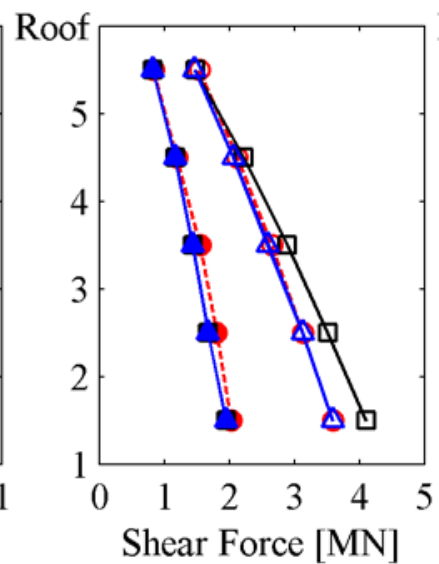

(b)

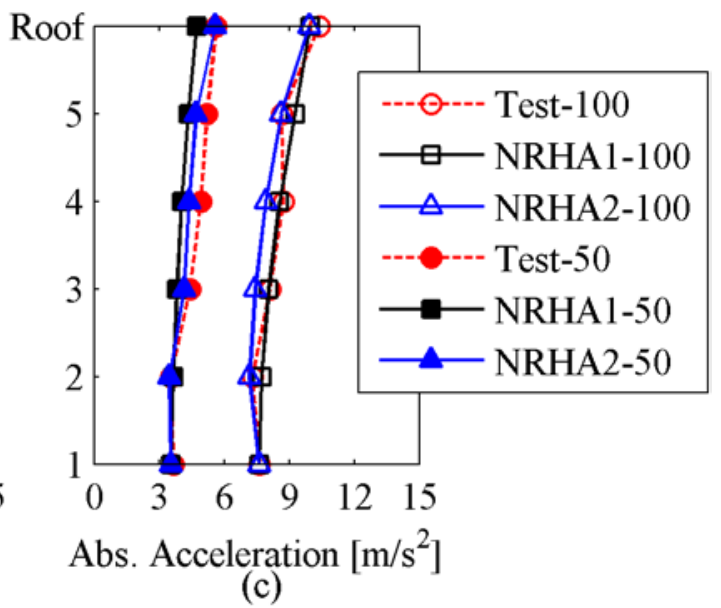

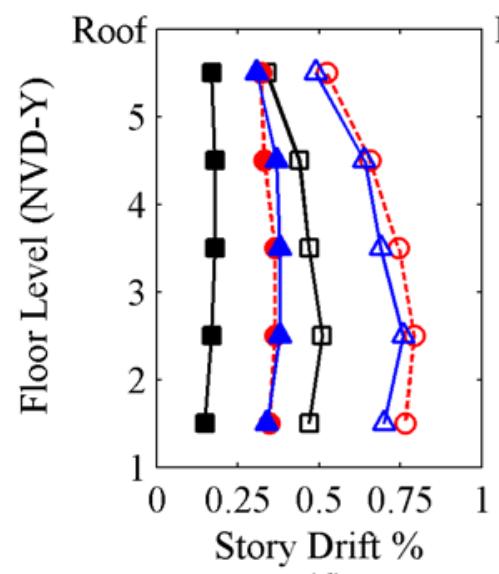

(d)

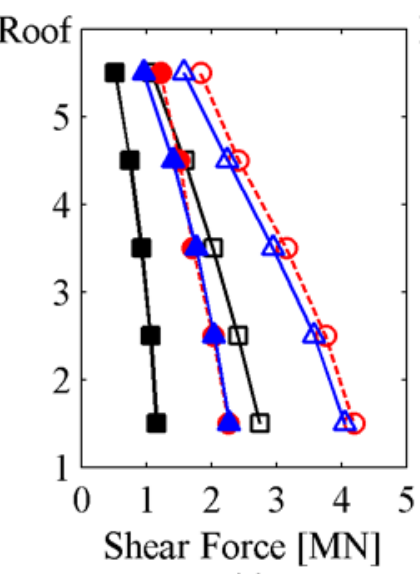

(e)

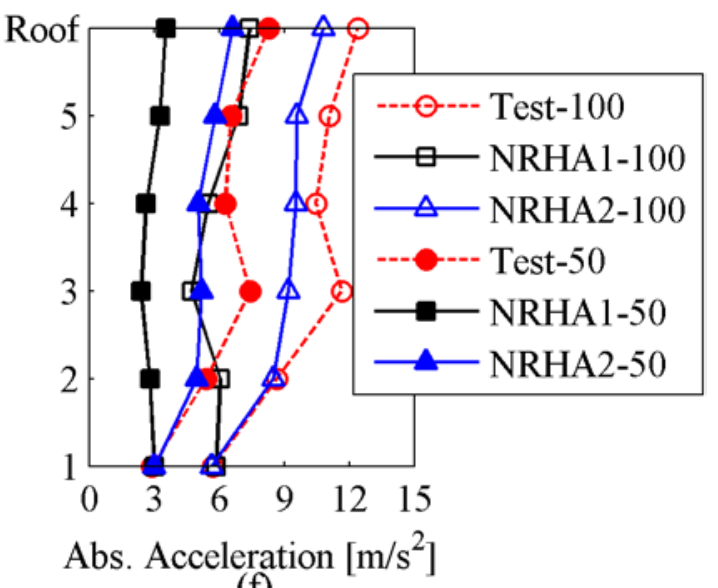

792

Figure 14: Comparison of computed and measured peak engineering demand parameters of the test

794 structure with nonlinear viscous dampers (50\% and 100\% JR Takatori record) 


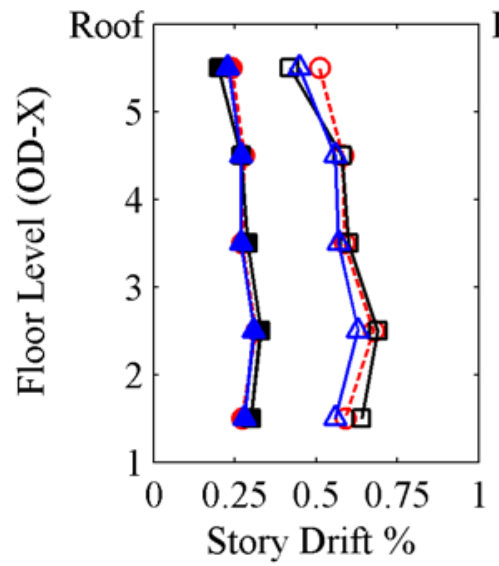

(a)

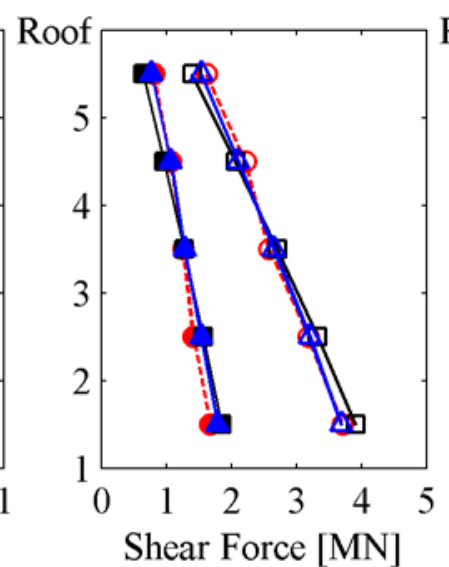

(b)

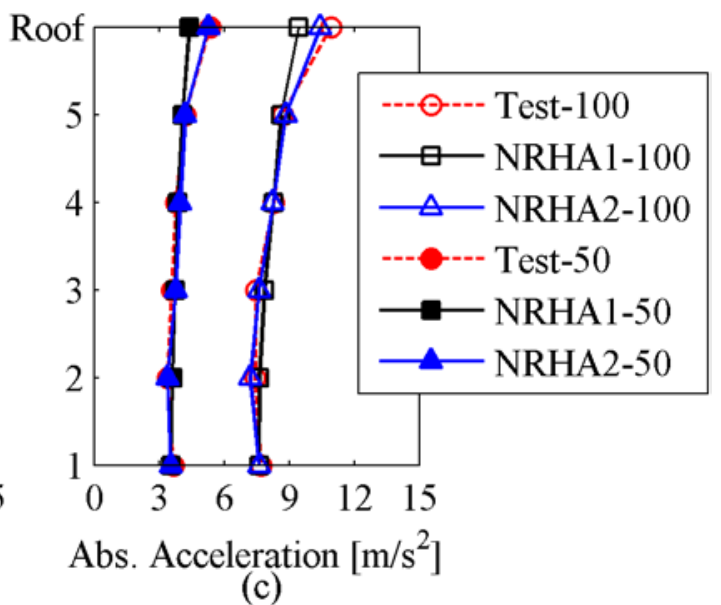

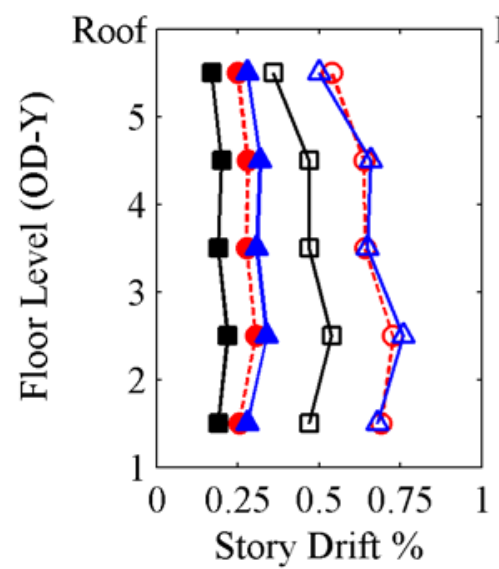

(d)

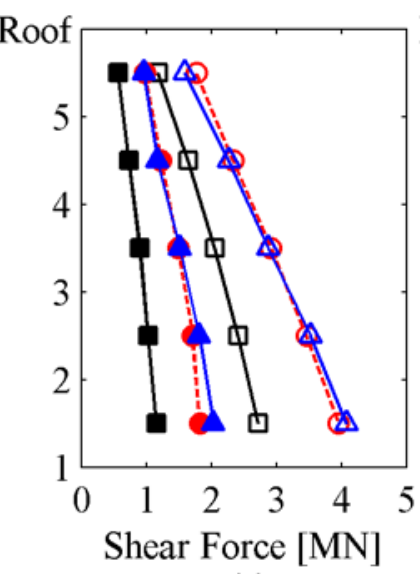

(e)

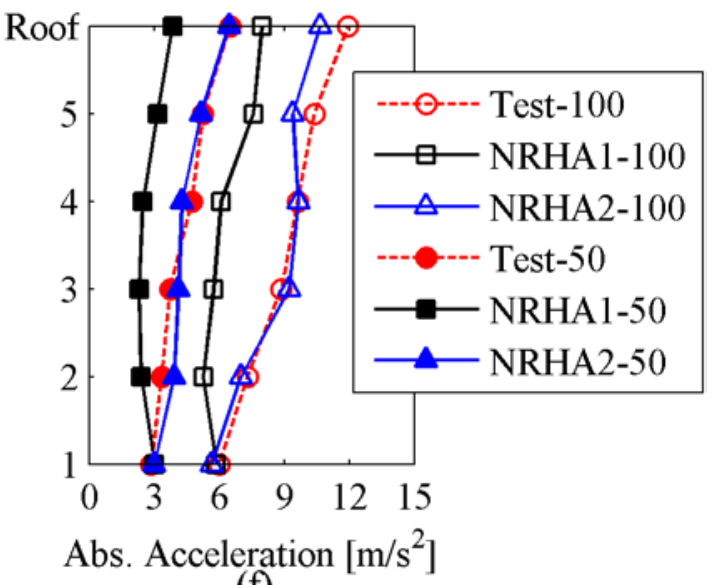

797

Figure 15: Comparison of computed and measured peak engineering demand parameters of the test structure with oil dampers (50\% and 100\% JR Takatori record) 


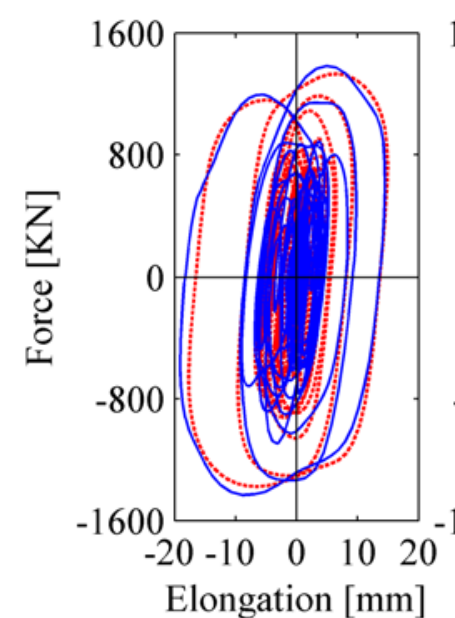

(a)

NVD

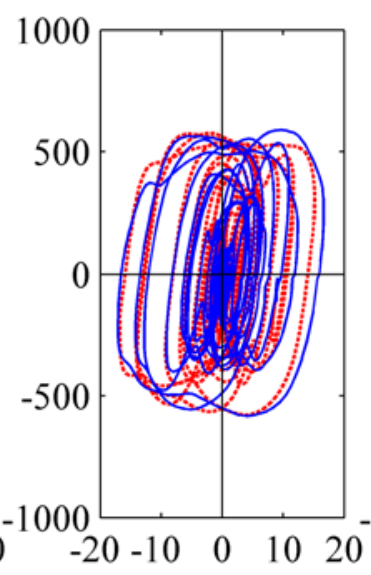

Elongation [mm]

(b)

NVD

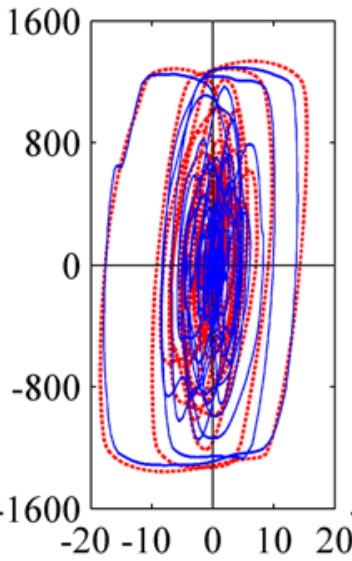

Elongation [mm]

(c)

Oil damper

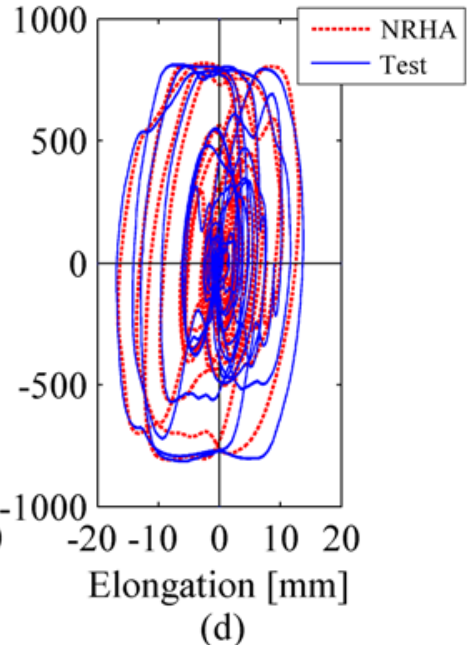

(d)

$\mathrm{X}$-loading direction

802 Figure 16: Comparison between the simulated and measured hysteretic response of nonlinear viscous and 803 oil dampers installed in the first story of the test structure (100\% JR Takatori record) 